\title{
La Sagrada Escritura como «Testamento» de Dios en la obra antidonatista de san Agustín
}

\section{INTRODUCCIÓN}

El día 12 de febrero del año 405, una ley del emperador Honorio declaraba oficialmente herejes a los donatistas que hasta entonces habían encontrado su refugio en la denominación de cismáticos ${ }^{2}$. Se les prohibía legar en testamento sus propiedades e igualmente recibir en herencia y ni siquiera les estaba permitido saltar la intención de la ley aceptando bienes de otros como regalos o donaciones ${ }^{3}$.

Otras leyes anteriores iban ya en esta dirección. Nos lo dice expresamente Agustín en su obra Contra Epistolam Parmeniani, escrita en torno al año 4004 . Tales leyes solamente en raras ocasiones fueron aplicadas. Como escri-

1. Codex Theodosianus XVI,6,4, PL 11,1206-1207: «Ideoque intercidendam specialiter eam sectam nova constitutione censuimus, quae ne haeresis vocaretur, appellationem schismatis praeferebat. In tantum enim sceleris progressi dicuntur ii, quos donatistas vocant, ut baptisma sacrosanctum, 'mysteriis recalcatis, temeritate noxia iterent, et homines semel, ut traditum est, munere divinitatis ablutos, contagione profanae repetitionis interfecerint. Ita contigit $u$ t haeresis ex schismate nascereturn. El no ser considerados como herejes era esencial para los donatistas, porque de lo contrario caían automáticamente bajo la amplia legislación antiherética.

2. No era otra la intención de la ley que comenzaba con estas palabras: «adversarios catholicae fidei exstirpare huius decreti auctoritati perspeximus» (ib.).

3. Ib.: «Sciant ii vero, qui ex supradictis sectis iterare baptisma non timuerint, aut qui consentiendo hoc facinus propria huius societatis permixtione damnaverint, non solum testandi sibi, verum etiam adipiscendi aliquid sub specie donationis vel agitandorum contractuum in perpetuum copiam denegatam, nisi pravae mentis errorem revertendo ad veram fidem consilii emendatione correxerint».

Leyes muy similares a éstas fueron promulgadas posteriormente en junio del año 414; cf. Codex Theod. XVI,5,54. Sobre todo esto, cf. W.H.C. FrEND, The Donatist Church, Oxford 1952, 263ss.; P. Brown, Agostino d'Ippona, Torino 1971, 230.

4. Contra Epistolam Parmeniani I, 12,19, PL 43,48: (Tras haber recordado algunas leyes 
be el santo, aunque en un contexto más amplio, «no faltaban las leyes, pero era como si no existiesen, porque estaban inactivas en nuestras manos. Tales eran las que se aplicaron contra vuestro obispo Crispino, no tanto para castigar su audacia, como para manifestar nuestra mansedumbre»" ${ }^{5}$.

Es fácil de comprender el efecto que la mencionada ley produjo en los ánimos de los afectados. Las páginas agustinianas evidencian por una parte el dolor que les produjo el hecho ${ }^{6}$, y por otra la ira hacia los emperadores cristianos ${ }^{7}$ y las acusaciones lanzadas contra los católicos, a los que los donatistas acusaban de ambicionar sus propios bienes y haber forzado la ley para quedarse con ellos ${ }^{8}$. La defensa de Agustín no es menos enérgica que las acusaciones de la parte contraria ${ }^{9}$. El santo admite la posibilidad de que haya quienes se comporten de tal modo, pero al mismo tiempo que recuerda a su interlocutor donatista que desaprueba la conducta del hipotético sujeto, le advierte que no le será fácil demostrar su acusación ${ }^{10}$.

Tal ley debió de alterar la vida ordinaria de las gentes más de lo que ahora podemos pensar. Y es de suponer que en su actividad episcopal Agustín tuvo que mediar en más de uno de los conf'ictos provocados por la situación. No hay que olvidar que en aquel entonces el obispo se había convertido en el juez de la ciudad ${ }^{11}$, oficio que a Agustín le resultaba desagradable en extremo ${ }^{12}$, como tampoco el tiempo que según san Posidio empleaba en tal función ${ }^{13} \mathrm{y}$ el

que podían aplicarse perfectamente al donatismo, continúa) «Sunt et aliae iussiones generales, quibus eis vel faciendi testamenta vel per donationes aliquid conferendi facultas adimitur, vel ex donationibus aut testamentis aliquid capiendi».

5. Contra Cresconium donatistam III, 47,51, PL 43,524: «...leges quae non deerant, sed quasi deessent, in nostris manibus quiescebant, adversus Crispinum episcopum vestrum commotae sunt, magis ut nostra mansuetudo demonstraretur, quam ut illorum puniretur audacia». Cf. FREND, 249-250.

6. Sermo 47,22, CC 41,595-596: «Condoles testamento tuo, si non stet ... in domo tua» ... «doles tamen non stare testamentum tuum» ... «doles quia adquisitionem tuam tollit alius quem nolebas".

7. Ib.: «Irascimini christianis imperatoribus, quia testamenta vestra valere noluerunt in domibus vestris».

8. Contra Litteras Petiliani II, 59,133, PL 43,304: «Petilianus dixit: 'dictum est: Non concupisces rem proximi tui (Ex 20,13-17). Vos nostra diripitis, ut pro vestris habeatis». Epistola 185,9,35; CSEL 57,31: «Quod autem nobis obiiciunt quod res eorum concupiscamus et auferamus... Ipsi certe dicunt, et invidiosissime sibi conqueri videntur quod eos in nostram communionem violento legum imperio coarctamus. Hoc utique nullo modo faceremus si res eorum possidere vellemus»).

9. Cf. nota anterior.

10. Epist. 93,12,50, CSEL 34/2, 493-494: «Sed tamen quisquis ex occasione huius legis, quam reges terrae Christo servientes, ad enmendandam vestram impetatem promulgaverunt, res proprias vestras cupide appetit, displicet nobis... Sed nec facile ista mostratis, et si monstretis, nonnullos tolleramus, quos corrigere vel punire non possumus».

11. Sermo $161,4, \mathrm{PL} 38,879 ; 167,3,4$, PL 38,911; Enarratio in psalmum $25,2,13$, CC 38,150. F. van der MEer, San Agustín pastor de almas, Barcelona 1965, 340ss. P. Brown, 222.

12. Cf. Epist. 48,1, CSEL 34,137.

13. Vita Augustini 19,2-3 (ed. Pellegrino, 1955,112): «Interprellatus ergo a christianis vel a 
hecho múltiplemente atestado en sus páginas de que a su palacio acudía toda clase de personas ${ }^{14}$.

Estos son los hechos. Ante ellos era obvio pensar que iban a repercutir de alguna manera, desde el punto de vista doctrinal, en la obra agustiniana tan sensible a cuanto se movía a su alrededor. De todos es conocido que sus numerosos escritos no son especulaciones de gabinete, sino respuesta a los problemas de distinta indole que le acuciaban a él o a otros que recurrían a su ciencia en busca de soluciones.

En realidad así ha sido. Bástenos con anotar la forma precisa en que repetidamente hace alusión a la legislación antes mencionada, es decir, estableciendo una comparación cuyos elementos originarios son el testamento humano y el testamento divino, concretizado este último en la Escritura.

Ahora podemos ya precisar con exactitud lo que constituirá el centro de nuestra atención: la comprensión que Agustín tiene de la Escritura como testamento de Dios y la utilización que en contexto antidonatista hace de esta idea.

Hay que precisar todavía un poco más. Cuando hablamos de «testamento» no nos referimos al sentido específicamente cristiano, según el cual decimos Antiguo o Nuevo Testamento. En esta utilización el término es sinónimo de alianza, pacto. T estamento, para nosotros, equivaldrá al «acto unilateral y personalísimo, solemne y revocable, en el que se contiene necesariamente la institución de uno o varios herederos y pueden ordenarse, además, otras disposiciones para que tengan efecto después de la muerte del testador» ${ }^{15}$. Tomamos la palabra en esta específica significación legal, pues san Agustín ha sido uno de los primeros que ha sabido ver claramente estas dos acepciones del término «testamento» ${ }^{16}$.

cuiuscumque sectae hominibus causas audiebat diligenter ac pie... Et eas aliquando usque in horam refectionis, aliquando autem tota die ieiunans, semper tamen noscebat et dirimebat...". Cf. también Epist. 139,3, CSEL 44,153.

14. En. in Ps. 46,5, CC 38,532: «Omnes pertinentes ad hereditatem Christi... et omnes non pertinentes ad hereditatem Christi... et videtis sic exaltari in nomine Christi Ecclesia Christi, ut omnes nondum credentes in Christo, sub pedibus iaceant christianorum. Quanti enim modo currunt ad Ecclesiam nondum christiani rogant auxilium Ecclesiae; subveniri sibi temporaliter volunt...». Cf. también Epist. 139,3, CSEL 44,153; Sermo 137,14, PL 38,762 y el texto de S. Posidio citado en la nota anterior.

15. Asi define el testamento romano J. ARIAS Ramos, Derecho romano. II. ObligacionesFamilia-Sucesiones, 2. ${ }^{\text {a }}$ ed. revisada por J.A. ARIAS BONET, Madrid 1966, 801-802.

16. Sermo 82,6, CC 39,1142: «Simul adversus te testamentum disposuerunt. Testamentum sane in Scripturis non illum solum dicitur quod non valet nisi testatoribus mortuis, sed omne pactum et placitum testamentum vocabant». Locutiones in Heptateucum I,21,27; PL 34,491: «Amat Scriptura testamenti nomine pactum appellare». Cf. también I,26,28; VII,9,7, PL 34,493 y 539 respectivamente.

Sabido es que la palabra griega diathéke que en el griego clásico y helenístico popular tenía el valor de testamento es el término con que los traductores griegos del Antiguo Testamento traduje- 
El trabajo se desarrollará en dos partes fundamentales. Una primera consistirá en ordenar y analizar los textos al respecto. En la segunda se intentará elaborar el material recogido en la primera. Es decir, a la tarea de análisis seguirá la labor de síntesis.

\section{TEXTOS Y ANÁLISIS DE LOS MISMOS}

Ciertamente la consideración de la Escritura, en su conjunto o en alguna de sus partes como Testamento de Dios en los sermones y escritos del santo que siguen a la mencionada ley es frecuente. Recordamos: Contra Cresconium donatistam III, 63,70; 71,83; IV, 53,63; 58,70 ${ }^{17}$; Enarratio in psalmum 21,2,30 ${ }^{18}$; 54,21 19; Epistola 93; $19^{20}$; Sermo 47,22 ${ }^{21}$; 358,2 ${ }^{22}$; Enarratio in psalmum $88,1,28^{23}$; y el Sermo ad caesariensis ecclesiae plebem $1.5^{24}$. Ya muy posteriormente el falsario autor del libro Contra quinque haereses se sirve del lenguaje de Agustín pero en otro contexto ${ }^{25}$.

ron la palabra hebrea berît, que significaba pacto, alianza, contrato. El paso siguiente consistió en denominar Testamento (antiguo y nuevo) a toda la Biblia (cf. Diccionario de la Biblia, Barcelona 1963,1925). En lengua latina su uso es muy antiguo. Ya Tertuliano, en Contra Marcionem IV , 1,1, CC 1,545 nos indica que en su tiempo era frecuente llamar a la Escritura testamentum y que este término era más utilizado que el empleado por él mismo, a saber, instrumentum (cf. R. Braun, Deus christianorum. Recherches sur le vocabulaire doctrinal de Tertullien, Paris $1977^{2}$, 470). Un poco más tarde el también africano Lactancio, en sus Divinae Institutiones IV,20, PL 6,515 , nos indica por qué es posible hablar de ese modo: «...et in utroque (testamento) idem testator est Christus qui pro nobis morte suscepta nos haeredes regni aeterni fecit, abdicato et exhaeredato populo iudaeorum... Cum sit haereditas eius coeleste regnum...».

17. Esta obra fue escrita cuando las leyes antidonatistas del 405 eran «recentisimas». Cf. «Institutum Patristicum Augustinianum», Patrologia, III, Roma 1978.

18. Aunque ZARB (Chronologia Enarrationum Sancti Augustini in Psalmos, Malta 1948) lo coloca en el año 395 y H. RONDET («Essais sur la chronologie des Enarrationes in Psalmos de saint Augustin», Bulletin de littérature ecclésiastique 61 (1960) 111-127 y 258-286) en el 412-415, parece más probable la fecha de A.M. LA BONNARDIĖRE (Recherches de chronologie augustinienne, Paris 1965, 22ss), es decir, el 407.

19. ZARB lo fecha en el 395, mientras que RONDET lo retrasa hasta el 407-408. Cf., de este último autor, "Chronologie augustinienne. Le Sermon sur le Psaume 54», Theologie aus der Geschichte, Festschrift für Berthold Altaner, Sonderausgabe des Historisches Jahrbuches 77 (1957-1958) 403-407.

20. Fue escrita el año 408. Cf. A.M. La BonNARDiERE, Recherches, $21 \mathrm{ss}$.

21. Todos los autores coinciden en colocar este sermón como posterior al 405, aunque varíen un poco a la hora de concretizar más. Las opiniones diversas pueden verse recogidas en $\mathrm{P}$. Verbraken, Etudes critiques sur les Sermons authentiques de saint Augustin, Steenbruges, $1976,64$.

22. Es colocado por todos los autores en mayo del 411. Cf. P. Verbraken, Études, 149.

23. ZaRB lo fecha en el 411-412 y RONDET lo coloca precisamente en el 411 .

24. Fue predicado en el 418. Cf. Patrología III, 365.

25. Esta obra se halla en el volumen VIII de la edición de los Maurinos de las obras de san Agustín. Cf. más adelante, nota 51. 
Tambien se encuentra con anterioridad y en el mismo contexto antidonatista: Enarratic, in psalmum 24,14 ${ }^{26}$, Contra Litteras Petiliani I, 23,25; II, 8,20 ${ }^{27}$; De unitate Ecclesiae 6,11 ${ }^{27 \mathrm{a}}$; y en Enarratio in psalmum 36,3,18 ${ }^{28}$.

$Y$ no solamente en boca de Agustín. Aparece igualmente en boca de los donatistas, tanto antes de la mencionada ley: Contra Litteras Petiliani II, 8,20, como después: Contra Cresconium donatistam III, 71,83; IV, 50,60 ${ }^{29}$. Con más anterioridad todavía lo encontramos en boca de san Optato de milevi: De schismate donatistarum $V, 3$, en un texto que muy probablemente ha inspirado a san Agustín como veremos más adelante ${ }^{30}$.

Pasemos ahora a examinar los textos enumerados. Vamos a hacerlo por orden inverso al ahora propuesto.

\section{A) San Optato de Milevi}

Texto $n .^{\circ}$ 1: De schismate donatistarum $V, 3$ :

Este texto de san Optato se coloca en la discusión entre donatistas y católicos sobre la reiteración o no del bautismo. En esta disputa se hace necesario buscar un juez neutral. Un pagano no puede ser, pues desconoce los misterios cristianos; tampoco un judío en cuanto enemigo del bautismo cristiano. Si, pues, no se puede hallar tal juez en la tierra, cabría pensar que sólo en el cielo se podría encontrar. Pero no es necesario acudir allí, pues en el Evangelio tenemos el testamento de Dios. Es éste un punto en el que se puede establecer una comparación entre lo terreno y lo celestial. Mientras vive un hombre, padre de muchos hijos, es él quien les da órdenes; no es necesario aún el testamento. Así obró Cristo; mientras estaba en la tierra, él mismo ordenaba a sus Apóstoles lo que era conveniente. Jesús hizo lo que haría cualquier padre terreno: al hallarse a las puertas de la muerte, temiendo que al morir él, rota la paz, litiguen entre sí los hermanos, en presencia de testigos, traspasa su voluntad desde su corazón a punto de morir a unas tablas que van a durar. En el caso de que surja una disputa, no se va al sepulcro, sino que se recurre al testamento. De este modo, quien déscansa en el sepulcro, habla sin palabras desde las tablillas... En nuestro caso quien hizo el testamento está en el cielo; su voluntad ha de buscarse en el Evangelio, como si fuera su testamento ${ }^{31}$.

26. Fue compuesto en el 392.

27. Esta obra fue compuesta entre el 398 y el 401. Cf. Patrología, 363.

27a Compuesta en torno al 400 . Ib.

28. Fue predicada en Cartago en el 403.

A esta serie de textos en que habla expresamente de testamento podrían añadirse otros muy numerosos en que sin emplear el término trabaja con la idea y los términos que van adjuntos: herencia, heredero, etc. Pero no entra dentro de nuestras intenciones.

29. Para las fechas de ambos escritos, cf. notas 27 y 17 respectivamente.

30. Optato de Milevi es de una generación anterior a san Agustín. Cf. Patrologia 112ss.

31. De schismate donatistarum V,3, PL 11,1048-1049: «Vos dicitis, licet; nos dicimus, non 
Tenemos, pues, un testamento: el Evangelio, en el que se puede encontrar la última voluntad del testador, Cristo. No se menciona herencia alguna ni se habla de heredero. El texto concreto que citará a continuación es Jn 13,8 que da respuesta al problema que discutían católicos y donatistas.

\section{B) Los donatistas}

Entre las invectivas de Petiliano figura ésta: «Si entregaras a las llamas el testamento de un hombre muerto, ¿no serías castigado como falsificador? ¿Qué va a ser, pues, de ti que entregaste al fuego la ley santísima de Dios, es decir, del juez? ${ }^{32}$. De la comparación resulta evidente que Petiliano considera la ley de Dios, la Biblia o Escritura, como un testamento.

En dos lugares de su obra contra el donatista Creconio, Agustín recuerda una pregunta que éste le formuló: «¿Quién está más lejos de asentir al testamento hecho, el que sufre persecución o el que la provoca?» ${ }^{33}$. En ambos casos Agustín responderá con un argumento ad hominem tomado de la historia de las relaciones entre el catolicismo y el donatismo y de la historia interna de este último ${ }^{34}$. No cabe duda en ningún caso de que el testamento a que hace referencia es la Escritura como se deduce del conjunto de textos que vamos a ir citando.

\footnotetext{
licet. Inter licet vestrum et non licet nostrum nutant et remigant animae populorum. Nemo vobis credat, nemo nobis: omnes contentiosi homines sumus. Quaerendi sunt iudices; si christiani, de utraque parte dari non possunt; quia studiis veritas impeditur. De foris quaerendus est iudex; si paganus, non potest christiana nosse secreta; si iudaeus, inimicus est christiani baptismatis; si ergo in terris de hac re nullum poterit reperiri iudicum, de coelo quaerendus est iudex. Sed ut quid pulsamus ad coelum, cum habemus hic in evangelio testamentum? Quia hoc loco recte possunt terrena coelestibus comparari. Tale est quod quivis hominum habens numerosos filios, quamdiu pater praesens est, ipse imperat singulis; non est adhuc necessarium testamentum. Sic et Christus, quamdiu praesens in terra fuit (quamvis nec modo desit), pro tempore quidquid necesssarium erat Apostolis imperavit. Sed quomodo terrenus pater, dum se in confinio senserit mortis, timens ne post mortem suam, rupta pace, litigent fratres, adhibitis testibus, voluntatem suam de pectore morituro transfert in tabulas duraturas; et si fuerit inter fratres nata contentio, non itur ad tumulum, sed quaeritur testamentum; et qui in tumulo quiescit, tacitus de tabulis loquitur. Vivus cuius est testamentum, in coelo est; ergo voluntas eius, velut in testamento, sic in Evangelio requiratur...»
}

32. Contra Litteras Petiliani II, 8,20, PL 43,264: «Si hominis mortui testamentum flamis incenderes, nonne falsarius punireris? Quid de te ergo futurum est qui sanctissimam legem Dei iudicis incendisti?».

33. Contra Cresconium donatistam III, 71,83, PL 43,541: «Et modo me interroga, quod in epistola tua post multa similiter inane posuisti, 'Quis prolato testamento minus consentit? Qui persecutionem patitur an qui facit?'». 'Cf. también IV, 50,60, PL 43,580.

34. Es decir, la persecución de Ceciliano por parte de los donatistas en el primer texto y, en el segundo, la que sufrio Salvio por obra de Restituto, ambos donatistas. 
C) Los textos agustinianos

1) Los anteriores al año 405

a) Dirigiéndose a los católicos

Texto.$^{\circ}$ 2: Enarratio in psalmum 24,14:

Se trata de una breve paráfrasis del versillo 14 del Salmo 24: Y su testamento está allí para que les sea manifiesto. Su testamento, comenta Agustín, se hace manifiesto, porque la herencia de Cristo son los pueblos y los confines de la tierra ${ }^{35}$.

Hay, pues un testamento (de Dios)

un heredero: Cristo

una herencia: los pueblos y confines de la tierra.

Texto n. 3: Enarratio in psalmum 36,3,18:

Agustín invita a los católicos a conservar la herencia. Ello les dará la seguridad de mantenerse dentro del testamento paterno, es decir, de lo establecido no en un papel cualquiera, sino en el documento del padre. Tal seguridad radica en el hecho de que vive aún el testador y él será quien lo interprete, obviamente en favor del que ha establecido como heredero. Es éste un punto a considerar: la diferencia entre el testamento humano y el divino. En el primero, uno es el testador, otro el juez, y quien tiene el testamento vence ante otro juez distinto de quien lo hizo, que ya está muerto. De donde puede formular el argumento de minore ad maius: Si, con el testamento en mano, se sale victorioso ante un juez diverso, ¿cómo no se va a vencer ante un juez que se identifica con el testador? La seguridad de la victoria es total, puesto que juzgará el mismo que testó. Este no es otro que Cristo que murió, sí, pero vive ya para siempre ${ }^{36}$.

Resumiendo, existe: un testamento paterno: la Escritura ${ }^{37}$; un testador: Cristo;

35. En. in Ps. 24,14, CC 38,139: «Et testamentum ipsius ut manifestaretur illis. Et facit ut testamentum ipsius manifestaretur illis, quia hereditas Christi gentes sunt, et termini terrae».

36. En. in Ps. 36,3,18, CC 38,379-380: «Tamen, fratres, ante omnia custodite hereditatem nostram, de qua securi sumus nos in testamento patris nostri esse: non in aliqua charta frivola alicuius hominis, sed in testamento patris nostri. Inde securi sumus, quia qui fecit testamentum, vivit; qui fecit testamentum heredi suo, ipse iudicabit de testamento suo. In rebus humanis alius est testator, alius iudex; et tamen qui tenet testamentum, vincit apud iudicem alterum, non apud alterum iudicem mortuum. Quam ergo secura est nostra victoria, cum ille iudicabit qui testatus est! Etsi enim mortuus est Christus ad tempus, sed iam vivit in aeternum».

37. En concreto, el Salmo que ha comentado y le ha dado pie para disputar contra los donatistas, en especial en el segundo sermón. 
una herencia: la Católica ${ }^{3 \%}$;

un juez: Cristo.

\section{b) Dirigiéndose a los donatistas}

Texto n." 4: Contra Litteras Petiliani I, 23,25

En este texto Agustín habla de los siguientes elementos: un testamento: la Escritura ${ }^{24}$, en concreto, Gen 22,18:

un testador: Dios:

un heredero: Abrahán y su semilla, es decir, Cristo;

una herencia; la bendición de todos los pueblos;

un intérprete auténtico y veraz: San Pablo;

validez actual del testamento: Nadie es capaz de hacer nula con su traditio la fidelidad de Dios.

En esta ocasión, como en otras que examinaremos, Agustin pasa del testamento materialmente entendido - el libro de las Escrituras - sobre el que se apoyaban los donatistas, al testamento en cuanto contenido o disposición expresada en él. Sobre esto se basa su polémica y se defiende de la acusación que le lanza el adversario. Puede gloriarse de haber librado el testamento de las llamas sólo aquél que respeta lo establecido en el mismo; en este caso concreto, la comunión con todos los pueblos. ¿Qué parte ha de considerarse que entregó el testamento al fuego, sino la que no quiere acordarse con lo escrito en él? No es, por tanto, temeridad alguna afirmar que son sucesores de aquellos traditores ${ }^{40}$, quienes ahora persiguen con la lengua el testamento que aquellos entregaron a las llamas para evitar la persecución ${ }^{41}$

38. En el número siguiente, Agustín pregunta: «Numquid catholica ego sum? Numquid hereditas Christi diffussa per gentes ego sum" (En. in Ps. 36,3,19, CC 38,380).

39. Los donatistas acusaban a los católicos de haber dado a las llamas la Escritura, el Testamento. Es de todos conocido que en el origen de la controversia donatista está la célebre traditio de los Libros Sagrados a las autoridades paganas que los entregaban al fuego. Cf. FrEND, The donatist Church, 19ss. nas.

40. Los traditores eran los que habían entregado los libros sagrados a las autoridades paga-

41. Contra Litteras Petiliani 1, 23,25, PL 43.256-257: “Postremo testamentum a quibusdam persecutione tempore flammis traditum perhibetur: ninc undecumque prolatum est recitetur. Certe in exordio promissiomum testatoris id invenitur Abrahae dictum: In semine tuo benedicentur omnes gentes (Gen 22,18); et hoc quid sit, verax interpretatur Apostolus: In semine, inquit, tuo, quod est Christus (Gal 3,16). Nullius traditio fidem Dei evacuavit. Communicate omnibus gentibus: et tunc vos testamentum a pernicie flammarum conservasse gloriamini. Si autem non vultis, quae pars potius credenda est, quod testamento institerit exurendo, nisi quae non vult consentire prolato? Quanto enim certius sine aliqua temeritate sacrilega, ille traditoribus sucessisse iudicatur, qui nunc lingua persequitur testamentum, quod illi flamma persecuti perhibentur?». 
Texto n. 5 : Contra Litteras Petiliani $11,8,20$ :

Agustín responde en este texto a la argumentación de Petiliano ya antes recordada: “¿no sería castigado como falsificador si hubieras entregado a las llamas el testamento de un hombre muerto? ¿Qué va a ser, pues, de ti, que entregaste al fuego la ley santisima de Dios?". Los elementos con que trabaja el santo son:

un testamento: la Escritura, en concreto Sal 2.8:

una herencia: todos los pueblos;

un heredero: Cristo;

coherederos: los católicos.

A la pregunta de Petiliano, que implica una acusación, Agustín responde llamándole la atención sobre un hecho, a saber: la posesión por parte de la Católica de la herencia formulada en el testamento. ¿Cómo es posible que habiendo dado el testamento a las llamas sean precisamente los católicos los que están en posesión de la herencia prometida en él? Y al mismo tiempo, ¿cómo los donatistas, habiéndolo salvaguardado, se ven privados de ella? Agustín insiste en que el testamento está en función de la herencia y que, por tanto, donde está ésta, se halla en definitiva aquél. Es, además, un absurdo gloriarse de haber salvado el testamento de las llamas, materialmente entendido, y después litigar contra las palabra del testador ${ }^{42}$.

En sus acusaciones contra los católicos, los donatistas les argüían incensantemente que si bien los contemporáneos de Agustín no habían entregado personalmente los códices al fuego, eran al menos los sucesores de quienes en otro tiempo lo hicieron. Agustín trata de volver la acusación contra ellos. ¿Quién es el auténtico sucesor de los traditores? Éste era el problema. El santo propone un criterio: Ha de considerarse heredero del traditor, aquel a quien se encuentre que no es coheredero de quien fue entregado (traditi cohaeredem), es decir, de Jesús. Puesto que la Biblia habla claramente (Lc 24,46) de la totalidad de los pueblos, como herencia y adquisición de Cristo, son los donatistas, al hallarse fuera de la herencia sin ser coherederos, quienes efectivamente son los herederos de los traditores. Todos los pueblos: tal es la herencia de la que ellos se anajenan; Cristo: he aquí el heredero al que ellos resisten. Puestos al lado de los judíos, son peores que ellos. Quien contradice a Cristo que está

42. Ib. II, 8,20, PL 43,264: «Inter multa tuae inventionis verba, dixisti: «Si hominis mortui testamentum flammis incenderes, nonne falsarius punieris? Quid de te ergo futurum est, qui sanctissimam legem Dei judicis incendisti?». Haec dicens non adtendisti quod te utique movere deberet, quomodo fieri potest ut nos testamentum incederemus et in ea haereditate consisteremus, quae illo testamento conscripta est; vos autem mirum est testamentum servasse, et haereditatem perdidisse. Nonne in eo testamento scriptum est, Postula a me et dabo tibi gentes haereditatem tuam, et possessionem tuam terminos terrae (Ps 2,8)? Huic haereditati communica, et obiice mihi de testamento quod voles. Nam quae dementia est, ideo testamentum tradere te noluisse flammis, ut contra verba litiges testatoris?». 
ya sentado en el cielo, ¿qué habría hecho con él cuando aún caminaba en la tierra? ${ }^{43}$.

Texto n. ${ }^{\circ}$ 6: De unitate Ecclesiae 6, 11:

Después de citar Gal 3,15-16 continúa: «He aquí el testamento de Dios» y trascribe a continuación el texto de Pablo: Nadie puede anular o añadir algo al testamento hecho en regla de un hombre. Ahora bien, los donatistas han hecho lo uno y lo otro con el testamento de Dios. Lo han hecho nulo: a) afirmando que no se ha cumplido en todos los pueblos; b) diciendo que la semilla de Abrahán ha desaparecido de aquellos pueblos en que había sido plantada. Han añadido algo afirmando que en ningún lugar se halla Cristo, el heredero, sino allí donde tiene a Donato por coheredero. Una vez más, como en el texto anterior ${ }^{44}$, los coherederos son un criterio para juzgar. Pero Agustín, muy prudentemente, les pide textos escriturísticos en que se exprese claramente que han de ser coherederos de Donato ${ }^{45}$. De todo lo dicho, resulta: un testamento en regla: la Escritura, en concreto Gen 22,18;

un testador: Dios;

una herencia: toda la tierra;

un heredero: Cristo;

coherederos: no los de Donato.

43. Ib., 265: «Quapropter puto iustum esse quod postulo, ut testamentum Dei, quod iam olim apertum est, aliquantum advertamus et quem non invenerimus traditi cohaeredem, ipsum iudicemus traditoris haeredem; ille pertinet ad Christi venditorem, qui Christum negat orbis emptorem. Nempe quando se post resurrectionem discipulis demonstravit, et palpanda membra dubitantibus praebuit, hoc illis ait: Quoniam sic scriptum est et sic oportebat Christum pati et resurgere tertia die, et praedicari in nomine eius poenitentiam et remissionem peccatorum per omnes gentes, incipientibus a lerusalem (Lc 24,46-47). Ecce a qua haereditate vos alienatis; ecce cui haeredi resistitis. Itane vero parceret Christo in terra ambulanti, qui contradicit in coelo sedenti? Adhuc non intelligitis quoniam quidquid nobis obiicitis sermoni eius obiicitis?":

44. Cf. nota 42.

45. De unitate Ecclesiae 6,11, PL 43,399: «Quaerimus enim iam quemadmodum intelligendum sit semen Abrahae. Fratres, inquit, secundum hominem dico, tamen hominis confirmatum testamentum nemo irritum facit, aut superordinat. Abrahae dictae sunt promissiones et semini eius. Non dicit: et seminibus, tanquam in multis; sed tanquam in uno: in semine tuo, quod est Christus (Gal 3,15-16). Ecce in quo semine benedicuntur omnes gentes. Ecce testamentum Dei: aperite aures. Hominis, inquit, confirmatum testamentum nemo irritum facit, aut superordinat. Quare vos irritum facitis testamentum Dei, dicendo nec in omnibus gentibus esse completum, et periisse iam de gentibus in quibus erat semen Abrahae? Quare superordinatis dicendo, in nullis terris haeredem permanere Christum, nisi ubi potuit cohaeredem habere Donatum? Non invidemus alicui: Legite nobis hoc de Lege, de Prophetis, de Psalmis, de ipso Evangelio, de apostolicis Litteris; legite et credimus; sicut nos vobis legimus et de Genesi et de Apostolo, quia in semine Abrahae, quod est Christus, benedicuntur omnes gentes». 
2) Los posteriores al año 405

a) Textos más tardíos

Texto n. ${ }^{\circ}$ 7: Enarratio in Psalmum 18,2,5

En este texto, Agustín nos habla de los elementos siguientes: un testamento paterno, claro y manifiesto: la Escritura, en concreto, Sal 18,5

un expositor, que no es necesario;

un heredero: quien tiene a Dios por Padre.

A partir de aquí, pasa a recordar a los donatistas cómo su conducta es contraria a sus mismos intereses. Pudiendo poseer todo, se contentan con una parte y es esto último lo único que les mantiene en la disputa ${ }^{46}$.

\section{Texto n. ${ }^{\circ}$ 8: Sermo ad caesariensis ecclesiae plebem 1.5:}

En línea de principio, dice Agustín, todos afirman querer lo que quiere Dios. Pero, ¿qué es lo que quiere Ell? ¿Cómo llegar a conocerlo? No es difícil: Basta leer el testamento de quien nos nombra coherederos. Aparecen en el texto los mismos elementos de siempre: un testamento: la Escritura, en concreto, Jn 14,27;

una herencia: la paz indivisible;

un testador: se sobreentiende Cristo;

coherederos: los cristianos ${ }^{47}$.

b) Textos contemporáneos de la ley

Texto $n .^{\circ}$ 9: Enarratio in psalmum 21,2,30:

De este largo texto resulta la existencia de los elementos de siempre: un testamento: la Escritura; en concreto, el Salterio; específicamente Sal 2;

46. En. in Ps. 18,2,5, CC 38,109: «In omnem terram exivit sonus eorum, et in fines orbis terrae verba eorum ... O superbe fili, audi testamentum patris tui. Ecce quid planius, quid apertuis? In omnem terram exivit sonus eorum et in fines orbis terrae verba eorum. Numquid expositore opus est? Quid contra te conaris? Partem vis in lite retinere, qui potes totum in concordia retinere?».

47. Sermo ad caesariensis ecclesiae plebem 1, PL 43, 689: «Hoc omnes volumus quod vult Dominus. Quid autem velit Dominus occultum non est. Legitur enim testamentum eius, qui nos sibi fecit cohaeredes; in eo recitatur: Pacem meam do vobis, pacem meam relinquo vobis (Jn 14,27).

Ib. 5,694: "Quid interest ergo ubi baptismum acceperis? Baptismus meus est, dicit tibi Sara... Noli superbire, veni ad haereditatem, maxime quia ipsa haereditas non est illa haereditas quae data est filiis Jacob. Filiis Israel data est terra: quanto a pluribus possidebatur, tanto plus angustabatur. Haereditas nostra pax vocatur. Testamentum lego: Pacem meam do vobis, pacem

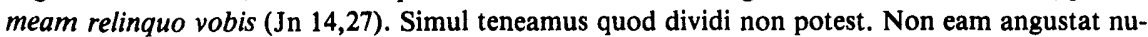
merosus possessor, quanticumque venerint, sicut promissum est: Sic erit semen tuum tanquam stellae coeli, et sicut arena quae est ad laterem maris. In semine tuo benedicentur omnes gentes... (Gen 22,18"). 
un testador paterno: El Padre o Cristo;

una herencia: todos los pueblos;

un heredero: Cristo o la Iglesia.

Pero veamos el empleo que hace de ellos. Una vez más, el contexto es la polémica sobre quién entregó al fuego las Escrituras, es decir, el testamento de Dios. Para dilucidar la cuestión, Agustín propone un criterio. Sea considerado traditor quien, tras haberse leído ese testamento, no manifieste haberlo cumplido. Una vez más Agustín se coloca en un plano distinto al de sus adversarios. ¿Quién, pues, lo mandó al fuego? ¿Quién le da fe y lo respeta o quien lamenta que exista para que pueda ser leído? Se impone, pues su lectura para saber quien lo ha respetado y quien no. Saquéselo de donde se quiera ${ }^{48}$ y léase. Esta disputa entre hermanos sobre una herencia tiene fácil solución, pues se conoce la voluntad del padre. Por fortuna, al morir dejó escrito su testamento. Agustín recurre a la praxis sobre la lectura de estos instrumentos legales ${ }^{49}$ y prosigue argumentando en su estilo diatríbico ${ }^{50}$ : si tanto valen las palabras de quien yace sin vida en el sepulcro, ¿puede uno atreverse a contradecir el testamento de Cristo que está sentado en el cielo? No queda, pues, más solución que leer el testamento paterno. No hay motivo para que siendo hermanos se esté siempre litigando. Se trata de saber dónde está la herencia para tomar posesión de ella. Para saber dónde está hay que conocer cuál es. Son todos los pueblos de la tierra, dice el testamento. Cumple el testamento quien está dentro de la herencia. El donatista ha de dejar la parte y entrar en posesión de la totalidad. Cristo ha anulado todos los límites o confines. Es absurdo buscarlos ahora como hacen los donatistas ${ }^{51}$.

48. Es una constante de Agustín. No tiene reparo, les dice a los donatistas, en tomar el testamento que ellos dicen haber conservado como juez imparcial. Cf. Contra Litteras Peliniani I, 23,25, PL 43,256-257 y la falsa interpretación que de estas palabras agustinianas da Cresconio en Contra Cresconium donatistam IV, 60,72, PL 43,588.

49. En. in Ps. 21,2,30, CC 38,132: «...et cum testamentum prolatum fuerit in publicum, tacent omnes, ut tabulae aperiantur et recitentur; iudex intentus audit, advocati silent, praecones silentium faciunt, universus populus suspensus est, ut legantur verba mortui, non sentientis in monumento..."

50. Me refiero al recurso al diálogo ficticio «le plus évident de tous les caractères formels» de la diatriba, según Oltremare (Les origins de la diatribe romaine, Lausanna 1926, 101. Sobre este aspecto de la diatriba puede verse W. CAPELlE-H. I. MARRou, voz Diatribe, en Realencyclopedie für Antike und Christentum 3,990-1009, en especial 992 b Form, 998 Struktur, c Form para la parte pagana y cristiana respectivamente. El uso de la diatriba por parte de Agustín ha sido estudiado por M. COMEAU, La Rhetorique de saint Augustin d'apres les Tractatus in Ioannem, Paris 1930, 23ss).

51. En. in Ps. 21,2,30, CC 38,131-132: «Si est adhuc quod dicant, nescio; litigent cum Scripturis, non nobiscum. Ecce codex ipse, contra illum certent. Ubi est lingua: Nos servavimus Scripturas, ne arderent? Servate sunt unde tu ardeas. Quid servasti? Aperi, lege: tu servasti et tu oppugnas. Quid servasti a flamma quod delere vis lingua? Non credo, non credo quia servasti; prorsus non credo, non servasti. Verissimi dicunt nostri quia tu tradidisti. Ille probatur traditor qui lecto testamento non sequitur. Ecce legitur et sequor; legitur et recusas. Cuius manus misit in 
Ante posibles objeciones del adversario, el santo sigue leyendo las restantes claúsulas del testamento para que no le quede escapatoria alguna ${ }^{52}$.

flammam? Qui credit et sequitur an qui dolet quia est quod legatur? Nolo scire quis servaverit; undecumque inventus est codex, testamentum patris nostri exiit de qualiber caverna; nescio qui fures tollere volebant; undecumque prolatum est, legatur. Quare litigas? Fratres sumus, quare litigamus? Non intestatus mortuus est pater. Fecit testamentum et sic mortuus est; mortuus est et resurrexit. Tamdiu contenditur de hereditate mortuorum, quamdiu testamentum proferatur in publicum... Ille sine sensu iacet in monumento, et valent verba ipsius; sedet Christus in coelo, et contradicitur testamento eius? Aperi, legamus. Fratres sumus, quare contendimus? Placetur animus noster, non sine testamento nos dimisit pater. Qui fecit testamentum vivit in aeternum; audit voces nostras, agnoscit suam. Legamus, quid litigamus? Ubi inventa fuerit ipsa haereditas, ipsam teneamus. Aperi testamentum; lege in primo capitulo ipsius Psalterii: Postula a me (Ps 2,8). Sed quis dicit? Forte non Christus. Ibi habes: Dominus dixit ad me, Filius meus es tu, ego hodie genui te (Ps 2,7). Ecce Filius Dei dicit, vel ad Filium suum Pater dicit. Ergo quid dicit ad Filium? Postula a me et dabo tibi gentes hereditatem tuam, et possessionem tuam terminos terrae. Solet fieri, fratres, ut quando quaeritur de possessione, quaerantur affines. Inter affines illum et illum, quaeritur heres, aut cui donatur, aut qui emit. Inter quos affines quaeritur? Inter illum et illum possidentes. Qui dimisit omnes fines, nullos dimisit affines. Quocumque te verteris, Christus est. Fines terrae habebis haereditatem, huc veni, totam mecum posside. Quare litigando vocas ad partem? Huc veni, bono tuo vinceris, totum habebis».

Es muy posible que Agustín se haya inspirado aquí en Optato de Milevi, en el texto citado con anterioridad en nota 31. De hecho sigue el mismo itinerario mental, aunque con más lógica, puesto que el Obispo de Hipona se apoya en textos bíblicos que le hablan de herencia y le permiten pensar en un testamento, mientras que Optato consideraba la Biblia como un testamento en sentido muy general, es decir, en cuanto que contenía la voluntad del Sefior. Así lo reconocía ya Fr. BALduINO al escribir: «Illud magis huius loci est, ut observemus Augustinum cautius quam Optatum uti superiori exemplo et comparationi. Optatus enim eo utitur cum ex novo testamento profert Scripturam Ioannis de lotione pedum ut inde probet non esse iterandum baptismum. Sed Augustinus qui vidit coactum id esse, mavult uti superior comparatione, cum ex Psalmis et Prophetarum scriptis probare vult Ecclesiam Christi esse catholicam...» (Annotationes in septem Libros Optati Milevitani, ex Fr. Balduini J.C. Commentariis rerum ecclesiasticarum 133, PL 11,1557 .

Por otra parte, de este mismo texto, aunque en otro contexto diferente, es decir, antiarriano, se sirve el autor de la obra Adversus quinque haereses Tractatus VI, PL 42,1108-1109: «In eo quod credit alium esse Patrem, alium Filium, alium Spiritum, mecum est contra Sabellianum. Age. Si mecum est in omnibus, quare litigamus? Si una nobis est haereditas, simul possideamus, fratres sumus... Quare est nova fabrica ante murum? Simus ad custodiam nostrae haereditatis, invigilemus... nemo sibi usurpet aliquid: haereditas ista sic est nobis dimissa, ut indivissa possideatur non partibus dissipetur. Simul fructum colligamus, ne dividendo perdamus... Mecum possidere putabatur, vult dividere, sed non permitto, prorsus resisto. Leges habent ut testatoris voluntati in omnibus pareatur: si quis contra voluntatem testatoris facere voluerit, careat haereditate... Testamentum profero, verba testatoris recito: si est quod dividatur, de ipso testamento tibi resisto. Audi quid habet testamentum: Pacem meam do vobis, pacem relinquo vobis (Jn 14,27). Haec est haereditas. Et quis est ipse testator? Lege testamentum et invenies ... (Miq 5,4; Lc 2,14). Ipse est haereditas, ipse testator, ipsum quaeris dividere. Quid partiris unum? Si unum divisseris, integrum nihil habebis».

Como ha podido verse recoge pensamientos esparcidos por la obra Agustiniana en textos ya citados aquí y otros que aún citaremos.

52. Ib.: «An adhuc calumniaris? Ego iam testamentum legi et tu calumniaris. An adhuc ca- 
Texto n. ${ }^{\circ}$ 10: Epistola 93,19:

De este texto se desprende que Agustín acepta la existencia de: un derecho divino, distinto del humano ${ }^{53}$; un testamento divino: la Escritura; en concreto, Gen 22,18;

una herencia: toda la tierra ${ }^{54}$;

un heredero: los hijos de Dios.

Es interesante el uso que hace de todas estas ideas. Agustín se justifica ante el rogatista Vicente de haber asentido a la política imperial de coerción frente a los donatistas y lo hace apoyándose en los óptimos resultados que desde su punto de vista había producido ${ }^{55}$. A partir de aquí continúa con una serie de preguntas en que pone frente a frente el derecho humano (romano) y el divino, un testamento humano y otro divino para mostrarles que en tales circunstancias no tenía más alternativa que optar por lo divino contra lo humano, por Cristo contra los donatistas.

¿Debía Agustín contradecir las disposiciones imperiales

- ¿para que los donatistas no perdiesen los bienes que llaman suyos y así, sin temor alguno, rechazasen a Cristo?

- ipara que legalizaran sus testamentos conforme al derecho romano y rompieran con imputaciones calumniosas el testamento legalizado con los Padres conforme al derecho divino, en el que está escrito: En tu semilla serán bendecidos todos los pueblos?

- ipara que en sus compraventas tuvieran libertad de contrato y se atrevieran a dividir en provecho propio lo que Cristo compró al ser vendido?

- ¿para que tuviese valor cualquier donación hecha por ellos y careciese de él la donación de Dios a sus hijos, que se extiende desde la salida del sol hasta su ocaso?

- ¿para que no fueran exiliados de la tierra de que procedían sus cuerpos e intentaran expulsar a Cristo del reino conquistado con su sangre, que va de mar a mar y desde el río hasta los confines de la tierra?

Agustín concluye con la defensa de los emperadores. Una de las formas

lumniaris quia fines terrae dixit, non dixit omnes fines terrae? Legamus ergo. Quomodo lectum est? Commemorabuntur et convertentur ad Dominum universi fines terrae. Et adorabunt in conspectu eius universae patriae gentium. Quoniam Domini est regnum et ipse dominabitur omnium gentium (Ps 2,28-29). Ipsius est, non vestrum. Agnoscite Dominum. Agnoscite possessionem Domini».

53. Cf. también, a este respecto, In Ioannis Evangelium Tractatus 6,25 , CC 36,66 .

54. Lo que aquí denominamos herencia se expresa en el texto también con otros términos: donación, conquista. Cf. nota 56.

55. Los expone en la misma Epistola 93,18, CSEL 34/2, 462-463. 
que tienen de servir a Cristo es dictar leyes en favor de Él. ¡Ojalá sigan haciéndolo! it.

\section{Texto n. ${ }^{\circ}$ 11: Sermo 47,22:}

El texto de Ezequiel 34,25: $Y$ dispondré para ellos un testamento de paz es el punto de arranque. En éste también largo texto agustiniano se habla de: un testamento paterno: de Cristo: Jn 14,27; de Dios: Gen 22,18;

una herencia: la paz indivisible, que es Cristo (Ef 2,14);

herederos: los cristianos; todos los pueblos;

Cristo ${ }^{56 a}$.

Estos datos son una excelente base para mantener una larga polémica con los donatistas, polémica alimentada por los acontecimientos del momento y llevada adelante en el estilo diatríbico tan típico del santo de que hicimos mención ${ }^{57}$.

Los donatistas, nos dice Agustín, se airaban contra los emperadores porque habían invalidado sus testamentos. Partiendo del convencimiento de que es Dios quien ha actuado por medio de la autoridad civil ya convertida a la fe cristiana, el santo se servirá de una especie de argumentación ad hominem: no tienen por qué quejarse; lo que han hecho los emperadores con los testamentos de los donatistas es lo que éstos han hecho con el testamento de Dios. A través de la acción imperial, Dios solamente quiso corregir, en ningún modo castigar. Quiso Dios compadecerse mediante su testamento de paz ${ }^{58}$. Es, por tanto, una corrección medicinal.

56. Epistola 93,19, CSEL 34/2, 463-464: «Ita sane huic provisioni contradicere debui ne res quas dicitis vestras perderetis, et securi Christum proscriberetis? ut iure romano testamenta conderetis, et iure divino patribus conditum testamentum, ubi scriptum est: In semine tuo benedicen. tur omnes gentes (Gen 22,18 ), calumniosis criminationibus rumperetis? ut in emptionibus et venditionibus liberos contractus haberetis, et vobis dividere quod Christus emit venditus auderetis? ut quod quisque vestrum cuiquam donasset, valeret et, quod donavit Deus deorum a solis ortu usque ad occasum vocatis filiis non valeret? ut de terra corporis vestri in exilium non mitteremini, et de regno sanguinis sui, a mari usque ad mare, et a flumine usque ad terminos orbis terrae (Ps $71,8)$ Christum exulem facere conaremini? Imo vero serviant reges terrae Christo, etiam leges ferendo pro Christo".

56a Sermo 47,22, CC 41,595: «Et disponam ad eos testamentum pacis, per ipsum utique qui ait: Pacem meam do vobis, pacem relinquo vobis. Hoc est testamentum patris nostri, testamentum pacis est. Quaelibet hereditas dividatur inter consortes, pacis hereditas dividi non potest. Pax nostra Christus est. Pax facit utraque unum, non duo de uno. Ipse enim pax nostra, dixit, qui fecit utraque unum (Eph 2,14). Testamentum Dei est, hereditas pax est. A concordibus consortibus possideatur, non a litigantibus dividatur. Et disponam ad eos testamentum pacis. Vigilate, haeretici, audite a pastoribus testamentum pacis, venite ad pacem». Véase también nota 50.

57. Cf. nota 50 .

58. Ib.: «Irascimini christianis imperatoribus, quia testamenta vestra valere noluerunt in domibus vestris. Videte quam digna sit poena. Et quid est quod testamentum vestrum non valet in domo vestra? Quid est? Quantum est? Dolor iste admonitio est, nondum damnatio. Voluit enim Deus compati testamento pacis suae». 
Buen rhetor avanza por medio de comparaciones:

Es comprensible, dice el santo a los donatistas, que sientan dolor al ver que sus testamentos permanecen inactivos. Pero han de considerar que se trata sólo de un testamento humano, del testamento de un hombre que ha de morir y que desconocerá lo que va a acontecer en su casa tras su partida de este mundo. Si el hombre se apena, ¿qué decir de Jesucristo quien tras haber muerto resucitó y desde el cielo vuelve su mirada a la tierra para ver si se cumple su testamento? ${ }^{59}$.

Por tanto, si el donatista tiene tanto interés en que se mantenga en vigor su testamento, ¿cómo o por qué no tiene idéntica preocupación porque se mantenga también en vigor el testamento de Dios en su casa (de Dios), es decir, su corazón (del donatista)? ${ }^{60}$.

Aunque se trata de cosas de poco valor en cuanto perecederas y sujetas a la ruina, cualquier hombre sufre si percibe que sus hijos van a actuar de distinta manera a como él había dispuesto y hace lo imposible por mantener su testamento. Se consultan abogados, se hace toda clase de trampas ${ }^{61}$ para mantener el testamento contra la ley del emperador, se buscan fórmulas de doble interpretación, etc. ${ }^{62}$.

Era de esperar la segunda parte de la comparación. Pero en este momento se introduce un nuevo interlocutor. Ya no habla Agustín. El santo cede la palabra a Dios quien entra en escena en diálogo con los donatistas:

- ¿Quieres tú que se mantenga en pie tu testamento? Mantén tú el mío. Si tú te dueles porque otro distinto del que tú querías llevó tu herencia, ¿qué diré yo de la mía, mucho mayor y más santa? Y a continuación, con aire de acusación, prosigue: Comuniqué mi testamento a mi siervo (Abrahán) y sin verlo lo creyó. Tú lo ves y lo niegas. El conservó el testamento hecho; tú, una vez abierto lo rasgas ${ }^{63}$.

59. Ib.: «Condoles testamento tuo si non stet testamentum tuum in domo tua. Certe moriturus est, et quid agatur in illa domo postea nesciturus... Non ergo sciturus quid postea agatur in domo tua cum mortuus fueris, doles tamen non stare testamentum tuum in domo tua. Christus mortuus resurrexit, de coelo respexit ut stet testamentum ipsius...".

60. Ib.: Doles, prorsus recte doles, non stare testamentum tuum in domo tua. Domus Dei cor tuum est. Si vis valere testamentum tuum in domo tua, quare non vis valere testamentum Dei in domo sua?».

61. No cabe duda de que aquí Agustín refleja la realidad de entonces y los recursos de que debían servirse los donatistas que tenian contra sí la ley.

62. Sermo 47, 22, CC 41,596: «Dimittis filiis tuis parietes, et si aliter filios tuos divisuros noveris, quam tu disposueris, doles. De una domo vilissima, de tecto ruituro, quantam curam habes, quantam sollicitudinem concipis: Quemadmodum ardentibus febribus, prementi morbo, ipsi morti urgenti resistis, quantum potes, anhelans verba extrema, ut impleas testamentum. Quot iurisperitos consulis, quantas fraudes, ut stet testamentum tuum contra ipsam legem imperatoris inquiris?".

63. Ib.: «De proximo tuo tibi respondet Deus: Noli fraudes quaerere, noli calumniosas formulas aucupari. Vis stare testamentum tuum? Stet in te meum. Doles quia adquisitionem tuam 
Finalmente es Agustín quien de nuevo toma la palabra y se dirige a los donatistas. Ciertamente quieren ser herederos. Han de considerar, pues, que sus coherederos no quieren dividir la herencia en partes, unas mayores y otras menores. No dicen: dividámosla, sino: poseámosla conjuntamente. No es ninguna novedad. Se trata sencillamente de cumplir la voluntad del testador ${ }^{64}$.

Ya como conclusión, Agustín sale al frente a las pretensiones donatistas de haber conservado ellos el testamento mientras los católicos lo entregaron a las llamas. El recurso del Obispo es el mismo de siempre: «Nunca creeré, dice, que ha conservado el testamento quien veo que no guarda lo que en él está preceptuado" " ${ }^{65}$. Una vez más, Agustín se coloca en otro plano, distinto, acompañándose del sarcasmo.

\section{Texto n. ${ }^{\circ}$ 12: Sermo 358,2:}

Un testamento: la Escritura; en concreto Sal 2,7-8 ${ }^{66}$;

una herencia y una posesión: los pueblos y la tierra entera;

herederos: Cristo y los cristianos, en cuanto miembros suyos.

Tales son los elementos que aparecen en este texto, quizá el más pacifista de todos, aquel en que la polémica está más apagada. Agustín exhorta a los donatistas a dejar de lado toda disputa sobre la herencia del Señor y recurrir al testamento del padre, pues sólo él podrá aclarar lo que está en duda y es objeto de discusión. Al mismo tiempo les invita a abandonar su espíritu de parte para abrazar la totalidad que caracteriza a la herencia ${ }^{67}$.

tollit alius quem nolebas. Quid de hereditate mea tam lata, tam pia? In semine tuo benedicentur omnes gentes (Gen 22,18), dixi ego servo meo, dicit, tibi Deus, et credidit cum haec non videret. $\mathrm{Tu}$ vides et negas. Ecce ille testamentum factum servabit, tu apertum discindis. Tunc enim testamentum servatum est, quando auditum est. Tunc apertum est, quando impletum est. Usque ad manus tuas servatum est testamentum».

64. Ib., 597: «Certe heres vis esse. Numquid sic tecum contendit coheres tuus, ut dicat tibi: "Tolle istam partem, ego illam», aut, "Tu minorem, et ego maiorem»? Non dicit: "Simul dividamus», sed: "Simul habeamus». Hoc enim voluit qui testatus est. Aperi et lege».

65. Ib.: «Et clamas: «Ne incenderetur, ego feci; ne incenderetur, ego servavi». Ne incenderetur, tu servasti? Aperi et vide quia unde indendereris servasti, quamvis te servasse absit ut credam, quem video non servare quod iubet. Et ponam ad eos testamentum pacis».

66. En este texto no emplea la palabra testamentum que hemos tomado como guía, pero sí su equivalente material tabulae.

67. Sermo 358,2, PL 39, 1586-1587: «Habemus verba Domini ... Dominus, inquit, dixit ad me: Filius meus es tu, ego hodie genui te. Postula a me, et dabo tibi gentes haereditatem tuam et possessionem tuam fines terrae» (Ps 2,7-8). Quare ergo, fratres, de possessione litigamus, et non potius sanctas tabulas recitamus? Venisse nos opinemur ad iudicem. De possessione contentio est; et haec contentio non litis sed dilectionis est. Denique litigator terrenae possessionis ad hoc litigat, ut excludat adversarium; nos ut intromittarnus. Litigator terrenae possessionis, cum audierit adversarium dicentem: «Possidere volo», respondet: «Non permitto». Ego autem fratri dico: «Possideas mecum volo»; ille litigando dicit: «Nolo». Non itaque timeo ne contemnat me Dominus, et corripiat, sicut illos fratres, vel illum fratrem, qui eum interpellavit in populo et ait: Domine, dic fratri meo ut dividat mecum haereditatem (Lc 12,13-15)... Istam correptionem non timeo. Inter- 
Los hasta ahora mencionados son los textos principales y más amplios, pero no son los únicos. Podemos recordar también los siguientes:

Texto n. ${ }^{\circ}$ 13: Contra Creconum donatistam III, 63, 70:

Gen 22,18 es interpretado, en conformidad con san Pablo (Gal 3,15-16) como el testamento de Dios. A la semilla de Abrahán, es decir, a Cristo, se le promete una fecundidad abundante (Gen 23,17). Es tan evidente su cumplimiento que hasta cierra la boca a los paganos; con todo, los donatistas osan anteponerle la parte de Donato ${ }^{68}$.

Texto n. ${ }^{\circ}$ 14: $I b . I V, 53,63$ :

Nadie, si hemos de creer al Apóstol (Gal 3,15), es capaz de anular o añadir algo al testamento de un hombre hecho en regla. Ahora bien, los donatistas se han atrevido a hacer lo uno y lo otro con el testamento de Dios ${ }^{69}$.

Texto.$^{\circ}$ 15: Ib. IV, 60,72:

En este texto explica cómo ha de entenderse una frase suya mal interpre-

pello enim dominum meum, fateor, interpello. Non tamen dico: Domine dic fratri meo ut dividat haereditatem mecum, sed dico: «Domine, dic fratri meo, ut teneat mecum unitatem». Ecce possessionis huius tabulas recito, non ad hoc ut solus possideam, sed ut fratrem meum nolentem possidere convincam. Ecce tabulas, frater: Postula a me, inquit, et dabo tibi gentes haereditatem tuam, et possessionem tuam fines terrae. Christo dictum est. Nobis ergo dictum est, quia Christi membra sumus. Quid curris in parte? aut quid remanes in parte? Ecce totum tene quod in tabulis. Quaeris inter quem et quem possideas, quomodo solent instrumentis quaeri possessores, inter quos sint affines. Qui tibi dedit omnes fines, nullos dimissit affines».

68. Contra Cresconium donatistam III, 63,70, PL 43,534: «Hoc enim posui in illa epistola, contra quam loqueris (Contra Litt. Pet. 1,23,25, PL 43,256-257), quod in sancto libro est de semine Abrahae, ad illum patrem nostrum dicente: In semine tuo benedicentur omnes gentes (Gen 22,18). Quod testamentum appellat Apostolus dicens: Fratres, secundum hominem dico, tamen hominis confirmatum testamentum nemo irritum facit aut superordinat. Abrahae dictae sunt promissiones et semini eius. Non dicit: "Et seminibus» tanquam in multis; sed tamquam in uno: In semine tuo quod est Christus (Gal 3,15-16). Huius seminis fecunditas tan copiosa promisa est, ut diceretur ei: Sic erit semen tuum sicut stellae coeli, et sicut arena maris quae non potest dinumerari (Gen 22,17). Huic tu multiplicationi atque ubertati Ecclesiae, quae toto orbe dilatatur, quae prophetata sic creditur, sic omnium etiam infidelim oculis exhibetur, ut claudat etiam ora paganorum... partem Donati audes praeponere, dicens quod et praeter Africam nescio quos habeatis...".

69. Ib. IV,53,63, PL 43,581-582: «Ausus es, inquam, testamento Dei reluctari, cum dicat Apostolus: Hominis testamentum confirmatum nemo irritum facit aut superordinat: Abrahae dictae sunt promissiones et semini eius $(\mathrm{Gal} 3,15)$. Hoc testamentum irritum facere, huic testamento partem Donati superodinare minime timuisti: ut cum Deus in eodem testamento dicat ad Abraham; Sic erit semen tuum sicut stellae coeli, et sicut arena maris (Gen 22,17); hoc tu irritum faciens, et partem Donati pro qua nullum testimonium recitas superordinans, "In paucis, inquis, frequenter est veritas; errare multorum est»; non intelligens quomodo a Domino dictum sit, paucos intrare per angustam portam (Mt 7,14)...». 
tada por Cresconio, a saber: «Léase en voz alta el testamento, venga de donde venga" (Contra Litt. Pet. I, 23,25) ${ }^{70}$.

\section{Texto n. ${ }^{\circ}$ 16: Enarratio in Palmum 54,21:}

Comentando el versillo 21 del Sal 54: Han manchado mi testamento, aprovecha la ocasión para recordar cuál es el testamento ( $=$ Gen 22,18 ), quienes lo han manchado ( = los donatistas) y cómo (afirmando contra las palabras del testador que sólo el Africa de Donato ha merecido tal gracia, que sólo en ella permaneció la Iglesia de Cristo). Los donatistas, por tanto, al abandonar la unidad de todos los pueblos y permanecer una parte han manchado el testamento de Dios "

Texto n. $^{\circ}$ 17: Enarratio in Psalmum 88,1,28:

Comentando ahora el versillo 29 del Sal 88, Agustín habla de:

un testamento: el Sal 88,27;

un testador: el Padre;

un mediador del testamento: Cristo;

un signatario: Cristo;

un fiador: Cristo;

un testigo: Cristo;

una herencia: Cristo;

un coheredero: Cristo ${ }^{72}$

En este breve texto no existe elemento polémico alguno.

70. Ib. IV , 60,72, PL 43,588: «Nam illud quam eleganter tibi visus es dicere, quod ego cum de testamento Dei dixissem, «Nunc undecumque prolatum est recitetur», respondendum putasti "quod iam hoc confessionem criminis habeat et ideo dixerim: A quocumque prolatum est recitetur, quia apud me constat, et a nostris exustum, et a vobis servatum atque prolatum»... Quod ergo dixi: "Testamentum undecumque prolatum est recitetur», non est confessio criminis, sed fiducia veritatis. Quid enim commodius, quid praeclarius, quam ut, si fieri potest, quod adversus te legatur, a te proferatur? Non quia ego non habeo pro me; sed facilior est certiorque convictio, ut tu habeas contra te, quod pro te, si corrigais, fiat».

71. En. in Ps. 54,21, CC 39,672: "Polluerunt testamentum eius. Lege testamentum quod polluerunt: In semine tuo benedicentur omnes gentes (Gen 22,18 )... Tu contra ista verba testatoris quid dicis? Africa sola istam gratiam meruit sancti Donati, in ipso remansit Ecclesia Christi... Polluerunt testamentum eius. Quod testamentum? Abrahae dictae sunt promissiones et semini eius. Apostolus dicit: Fratres, tamen hominis testamentum confirmatum nemo irritum facit, aut superordinat. Abrahae dictae sunt promissiones et semini eius; no dicit, Et seminibus, tanquam in multis; sed tanquam in uno: Et semini tuo quod est Christus (Gal 3,15-16). In hoc ergo Christo quod promissum est testamentum? In semine tuo benedicentur omnes gentes. Tu dimissisti unitatem omnium gentium, et in parte remansisti, polluisti testamentum eius. Quod tibi ergo contigit, ut exterminareris, ut ab haereditate separareris, de ira Dei est...".

72. En. in Ps. 88,1,28, CC 39,1232: «In aeternum servabo ei misericordiam meam, et testamentum meum fidele ipsi. Propter ipsum (Christum) fidele testamentum, in ipso mediatum est testamentum, ipse mediator testamenti; ipse signator testamenti, ipse fidei iussor testamenti, ipse testes testamenti, ipse cohaeres testamenti». 
Estos son los principales textos que hemos recogido en los que el santo considera la Biblia como testamento de Dios en el significado anteriormente anotado ${ }^{73}$. Hemos seguido el término testamento exclusivamente. La idea es mucho más amplia sin embargo, y para abarcarla toda hubiera sido preciso recorrer las páginas agustinianas tras los términos heredero y herencia al menos. Sin duda el resultado habría sido más completo, pero ello estaba fuera de nuestros planes iniciales.

\section{VISIÓN DE CONJUNTO DEL PENSAMIENTO AGUSTINIANO}

Después de haber ordenado los textos por orden cronológico ${ }^{74} \mathrm{y}$ haber hecho un ligero análisis de todos ellos, para comprender el pensamiento agustiniano en plenitud, es útil intentar dar una visión un tanto orgánica de lo encontrado en los distintos textos.

\section{A) La vida ordinaria fuera de la Iglesia}

«La atmósfera de una sala de audiencias acompaña a Agustín hasta cuando predica en la iglesia contra los donatistas" ${ }^{75}$. Nada extraño, si se considera el tiempo que dedicaba diariamente a ejercer la función de juez en su ciudad, como anotamos anteriormente ${ }^{76}$. De sus obras se pueden extraer también los problemas que más frecuentemente le ocupaban. "Tenía que tratar ante todo con casos intrincados y acrimoniosos de divisiones hereditarias. Era extremamente raro que hubiese acuerdo entre los hermanos a la hora de dividir el patrimonio paterno, y Agustín tenía que escuchar durante horas enteras las discusiones apasionadas de los miembros de las familias de agricultores sobre cada uno de los detalles de la voluntad paterna" ${ }^{77}$.

Esto que afirma P. Brown de forma muy general, podemos especificarlo un poco más, siguiendo los textos trascritos con anterioridad ${ }^{78}$. Hombres de toda categoría y credo religioso se acercaban al obispo de la ciudad discutiendo sobre alguna herencia ${ }^{79}$. En consecuencia, los sujetos de tales pendencias solían ser hermanos ${ }^{80}$. El recurso del juez (obispo) era preguntar dónde estaba el testamento, si lo había, y, una vez leído, en base a él dictar sentencia ${ }^{81}$.

73. Cf. nota 15.

74. Aunque sólo grosso modo sin entrar en prioridades cuando se trata de textos cercanos entre sí.

75. P. Brown, Agostino d'Ippona, 222.

76. Cf. nota 13.

77. P. Brown, Agostino d'Ippona, 222.

78. No cabe duda de que Agustín extrae de la vida diaria los ejemplos de que se sirve en su predicacion o escritos.

79. Cf., por ej., el texto.$^{\circ} 12$, nota 67 . De ahora en adelante citaremos así: 12 (67). El primer número se refiere al texto y el segundo a la nota en que viene trascrito.

80. Cf. 9 (51) y $12(67)$.

81. Cf. 3 (36). 
En el mismo podía hallarse la solución. Los interesados presentan las tablillas ${ }^{82}$; callan todos para que se abran y se lean; el juez escucha con atención; entre tanto se lee, los abogados callan ${ }^{83}$; los praecones ${ }^{84}$ imponen silencio, y todos los presentes están pendientes de lo que está escrito en el testamento ${ }^{85}$. Se hará como éste ordene y así se concluirá la contienda.

Pero otras veces el centro de la discusión no era una posesión o herencia, sino el testamento mismo. Posiblemente había que interpretarlo, pues podía darse que no estuviese todo claro. Quizá no estaba del todo manifiesto quién era constituido heredero ${ }^{86}$; había que ver si estaban redactados conforme al derecho romano ${ }^{87}$; se pregunta por la paternidad del mismo ${ }^{88}$, por la herencia, precisándola bien ${ }^{89}$, por los herederos ${ }^{90}$. Se ponderan bien las palabras; qué es lo que en realidad se halla escrito, pues nadie duda de que es una demencia litigar contra lo que está escrito en el testamento ${ }^{91}$. Pero no sólo hay que mirar las palabras; se trata también de salvar la voluntad del testador ${ }^{92} ; \mathrm{y}$ siempre hay que estar atentos a la posibilidad de la existencia de un falsificador ${ }^{93}$. Una vez aclarado en todos sus puntos el testamento, se dicta-

82. El testamento romano podía ser oral o escrito. Cf. J. ARIAS Ramos, Derecho 805-806. Cuando era escrito se hacía sobre las tabulae. De aquí que se denomine al testamento por este nombre. De todos modos, se trata de un término muy genérico que en cada caso se refiere a algo distinto, aunque siempre relacionado con documentos escritos. Agustín habla, por ejemplo, de tabulae matrimoniales (Sermo 9,18, CC 41,143; 37,6,7, PL 38, 225; 51,13,22, PL 38, 345, etc.), de las tabulae commerciales (In Io. Ev. Tract. 13,14, CC 36,138.

83. Ante una causa existía la función de asesoramiento y de defensa. La primera, desempeñada por los iurisconsulti, era más bien pre- o extraprocesual. La segunda la llevaba a cabo el $a d$ vocatus (J. Arias Ramos, Derecho, 169, n. 191). Es decir, el advocatus o abogado era el que con su elocuencia defendía a su cliente en la fase «apud judicem» (p. 203). La primera diferencia queda claramente expresada en el siguiente texto agustiniano: Epistola 153,6,22, CSEL 44,423: «Sed non ... quia vendit advocatus iustum patrocicium et iurisperitus verum consilium». La estrecha relación entre el advocatus y la elocuencia aparece también clara en la Enarratio in psalmum 136,3; CC 40,1965.

84. La función de los praecones era la de asistir a los magistrados; publicaban los edictos; se encargaban de citar a los reos, anunciar la llegada del juez (En. in Ps. 21,2,2, CC 38,123), imponer silencio en la sala (texto presente) y publicar la sentencia (In Io Ev. Tract. 13,16, CC $36,139 ; 45,9,36,393)$.

85. El texto latino se halla en n. 49. Sin duda Agustín no está reflejando aquí la praxis judicial tal y como se llevaba a cabo en su palacio, sino la praxis judicial ante la autoridad civil. El tribunal de Agustín era mucho más parco en personajes. Una y otra parte contendiente aceptaban en principio lo que dictase el obispo que en cierto sentido era juez y abogado de ambas partes. Las críticas, sin embargo no faltaron y quienes antes de dictar sentencia habían jurado aceptarla, una vez escuchada se olvidan de ello. Cf. el elocuente texto de En. in Ps. 25,2,13, CC 38,150.

86. Cf. 3 (36) y 4 (41).

87. Cf. $10(56)$.

88. Cf. $3(36), 7(46), 11$ (56a) y $9(51)$.

89. Cf. 9 (51).

90. Cf. 9 (51) y $12(67)$.

91. Cf. 4 (41).

92. Cf. $11(64)$.

93. Cf. 5 (42). 
mina en conformidad con él y se otorga a cada contendiente la parte que le corresponde, parte que a veces puede ser mayor aún de la que el interesado estaba defendiendo ${ }^{94}$.

\section{B) En el interior de la Iglesia}

Después de la lectura de los textos agustinianos no queda la menor duda de que el santo ha visto el conflicto entre el donatismo y el catolicismo como una amarga disputa entre dos hermanos que contienden por una herencia. De aquí la repetición de una pregunta: «Somos hermanos, ¿por qué litigamos?» ${ }^{95}$. La vía de solución propuesta por él no era otra que la de acudir a un juez para que él dicte sentencia en favor de uno u otro. El caso era parecido, pero en ningún modo idéntico a los que él solía juzgar. Normalmente las disputas versaban sobre una herencia o posesión que todos conocían y que todos igualmente querían poseer. En el caso concreto del donatismo y el catolicismo, en cambio, se trataba de conocer cuál es en realidad la herencia paterna de la que ambas partes contendientes creían estar en posesión. El donatismo disfrutaba de una posesión y pretendia que era la auténtica herencia legada en testamento por el Padré; la Católica disfrutaba de otra y tenía idéntica pretensión. Dado que no coincidían, es decir, dado que eran distintas y la herencia no era más que una, o bien la una o bien la otra no era la dejada por el Padre. Saber cuál era la auténtica, cuál la falsa: tal es el núcleo de la cuestión, tal el centro del litigio.

Agustín les propone el recurso ficticio al juez, sabiendo que va a preguntar antes que nada por el testamento por tratarse de una cuestión de herencias ${ }^{96}$. No hay mejor salida; quizá no existe otra salida. Es inútil discutir para averiguar quién está en posesión de la herencia. Sólo conociéndola puede averiguarse en manos de quien está. De aquí el recurso constante de Agustín al testamento. Una vez conocida, pueden resolverse los demás problemas. Quien la posea de hecho, será el heredero de derecho, porque el testamento de Dios no pudo no ser efectivo ${ }^{97}$. El testamento existe: el codex bíblico, testamentum patris nostri ${ }^{98}$. Cuando Agustín habla de tabulae en este contexto se refiere a la Escritura y no porque estuviese escrita en tablillas, sino porque al conside-

94. Como veremos que recuerda Agustín a los donatistas, pero en otro plano.

95. Cf. 9 (51) y 12 (67).

96. Para Agustín, el juez no es otro más que el testador, es decir, Cristo. Cf. 3 (36).

97. Cf. 4 (41).

98. Cf. 3 (36), 7 (46), 9 (51) y 11 (56a). Debe tenerse en cuenta que Agustín habla siempre de testamento del padre, aun cuando el testador no sea el Padre, sino Cristo (Cf. 3 (36), 11 (56a). La explicación para ello hay que buscarla en el derecho romano. Según éste, solo gozaba de capacidad de tener un heredero y, en consecuencia, de capacidad para testar, quien era, a la vez, libre,. ciudadano y paterfamilias (Cf. J. ARIAS RAmos, Derecho, 808 y 810). Un Filiusfamiliae no podia testar. Dice UlPIANO, Liber singularis regularum 20,10: «Filius familiae testamentum facere non potest, quoniam nihil suum habet ut testari de eo possit». 
rarla como testamento de Dios la designa por el medio en que éste solía efectuarse ${ }^{99}$.

\section{1) La Biblia «testamento" de Dios}

La concepción de la Escritura como testamento de Dios es, según se ha visto, muy frecuente. Recordamos ya que la concepción no es exclusivamente suya ${ }^{100}$. Él la encuentra en san Pablo (Gal 3,15). Dentro de la controversia donatista es formulada explícitamente por san Optato de Milevi ${ }^{101}$, por parte católica, y, por parte donatista, por Petiliano y Cresconio ${ }^{102}$

A pesar de esta coincidencia general hay que hacer notar algunas pequeñas divergencias. San Optato, en el texto citado, considera el Evangelio como testamento solamente en cuanto es expresión de la última voluntad de Jesús, sin referencia alguna a «bienes» de que disponga en concreto, ni a heredero que es, esto último, lo que constituía la esencia del testamento romano ${ }^{103}$. Los donatistas hablan ciertamente de consentire testamento ${ }^{104} \mathrm{y}$ lo entienden ciertamente en el sentido legal que es común a toda la tradición anterior ${ }^{105}$, pero no se detienen tanto como Agustín en el análisis del contenido del mismo ${ }^{106}$. Agustín habla efectivamente de la Escritura como testamento en sentido material ${ }^{107}$, pero insiste sobre todo en el contenido del mismo, en lo dispuesto en él por el testador. Su interés se centra en conocer la herencia, dónde se halla y, en consecuencia, en aquella disputa concreta, quién es el auténtico heredero de hecho, porque lo será también de derecho. Normalmente no denomina testamento a toda la Biblia, sino sólo a ciertos textos que le dan pie para ello como veremos a continuación.

Ese testamento divino no sólo existe, sino que también ha sido abierto ${ }^{108}$,

99. En tiempos de Agustin la Estia se hallaba escrita en codices, y codex es la palabra de que se sirve Agustín habitualmente para designar el libro materialmente entendido de la Biblia. Cuando la denomina tabula es debido a un contexto especial. Cf. n. 82.

100. Cf. notas $29-30$

101. Cf. 1 (31).

102. Cf. 4 (41) y $5(42)$.

103. Cf. 1 (31). Sobre la institución de heredero como elemento esencial y constituyente del testamento romano, cf. J. ARIAS Ramos, Derecho, 802. Gayo, en sus Istitutiones 2,229, dice así: "Ante heredis institutionem inutiliter legatur, scilicet qui testamenta vim ex institutione heredis accipiunt, et ob id velut caput et fundamentum intelligitur totius heredis institutio». Cf. también P. BONFANTE, Instituciones de derecho romano, Madrid 1929, 576.

104. Cf. n. 33.

105. Cf. n. 16.

106. Hay que tener en cuenta, sin embargo, que de los donatistas conservamos, en este contexto, sólo textos aislados que recoge la obra agustiniana.

107. Así cuando habla de las tabulae en 9 (5) y 12 (67).

108. La apertura del testamento era un acto solemne que requería ciertas formalidades. «A partir de la publicación de la Lex Iulia vicesimaria de Augusto, que estableció un impuesto gene- 
cuando se cumplió ${ }^{109}$. Nos es posible, por esto mismo, conocer más de cerca ese testamento en cuanto a su contenido se refiere.

Existe una doble serie de textos bíblicos de los que Agustín dice que son el testamento de Dios.

La primera está formada exclusivamente por Jn 14,27 110. Es fácil de comprender que Agustín hable en este contexto de testamento. Por una parte, el pasaje de san Juan tiene todo el carácter de una última voluntad de Jesús, quien, a punto de partir, dice a sus discípulos: Mi paz os dejo, mi paz os doy. Por otra, la relación establecida por el santo entre ese texto y Ez 34,25: Y dispondré para ellos un testamento de paz ${ }^{111}$ lo explica todo. Las palabras de Jesús hacen realidad la promesa anticotestamentaria de un testamento de paz.

La segunda es más variada. Comprende varios textos que coinciden en la idea de universalidad. Prevalece evidentemente Gen 22,18: En tu semilla serán benditos todos los pueblos ${ }^{112}$. Le sigue Sal 2,8: Pídemelo y te daré en herencia los pueblos y en posesión los confines de la tierra ${ }^{113}$. Luego Sal 18,5: Por toda la tierra resonó su voz ${ }^{114}$ y Sal 24,13: Su descendencia poseerá la tierra ${ }^{115}$. También aquí existe una doble base para que Agustín pueda hablar de testamento refiriéndose a estos textos. Por un lado, algunos hablan de heredad, de herencia ${ }^{116}$, que espontáneamente conduce a pensar en testamento. Por otro está el hecho de que san Pablo (Gal 3,15) habla de testamento refiriéndose a Gen 22,18, como Agustín mismo recuerda expresamente ${ }^{117}$.

Se puede avanzar un poco más y ver los contenidos de ese testamento tal como los expuso Agustín. De la doble serie de textos surgen varias líneas de pensamiento que podemos esquematizar de la siguiente manera:

a) La primera tiene las siguientes constantes:

el testador es Dios Padre;

ral del cinco por ciento sobre las herencias, la apertura del testamento no era un acto privado, sin formalidades, sino que ... se regularon sus requisitos. PAULO (Sentent. IV,6) nos los enumera: la apertura se verifica in foro vel basilica, tal vez en la oficina de récaudación de impuestos, ante la mayoría, al menos, de los testigos que intervinieron en el otorgamiento y dentro de un plazo de tres a cinco días del fallecimiento del testador. Reconocidos por los testigos los sellos y superscriptiones, se leía el testamento y quedaba archivado levantándose acta de la ceremonia» (J. ARIAS Ramos, Derecho, 823-824).

109. Cf. 11 (56a) y también 5 (43).

110. Cf. 8 (47) y 11 (56a) y, aunque apócrifo, el texto del Adversus quinque haereses recogido en la última parte de la nota 51 .

111. Así la traducción latina que él utilizaba. La Vulgata, más fiel al original hebreo $b^{e} r i t$, traduce pactum en lugar de testamentum.

112. Cf. $4(41), 6(45), 10(56), 11(63), 13(68), 14(69)$ y $16(71)$.

113. Cf. $5(42), 9(51)$ y $12(67)$.

114. Cf. 7 (46).

115. Cf. 2 (35).

116. Gen 22,18 ; Sal $2 ; 8 ; 24,13$.

117. Cf. $13(68)$ y también $6(45)$ y $14(69)$. 
la herencia, todos los pueblos y tierras;

el heredero es Abrahán y su semilla, es decir, Cristo, según la interpretación de san Pablo, a quien el santo considera como el verax intérprete $1 ! 8$.

Los coherederos son los cristianos porque son miembros de Cristo, es decir, forman su cuerpo ${ }^{119}$. Se puede ir más adelante y afirmar que sólo son miembros de Cristo los que son coherederos con él ${ }^{120}$.

b) Las constantes de la segunda línea son las siguientes:

el testador es Cristo ${ }^{\prime 2}$;

la herencia es la paz, o sea, Cristo mismo, según san Pablo (Ef 2,14). Herencia que, por tanto, es indivisible ${ }^{122}$.

Los coherederos son los cristianos. Todos participan en plenitud de la misma herencia ${ }^{123}$.

c) Una tercera línea mezcla las dos anteriores:

el testador es Cristo;

la herencia es la católica, todos lo pueblos;

herederos son los cristianos o la Iglesia misma ${ }^{124}$.

d) Existe una última línea en la que;

el testador es el Padre;

la herencia es Cristo;

el heredero es también Cristo;

el coheredero es igualmente Cristo ${ }^{125}$.

Aunque el santo no desarrolla el tema, es evidente que está pensando en categorías del Cristo Místico.

Esta variedad es fácil de comprender. Es el resultado de la diversidad de

118. Cf. $4(41)$.

119. Esto se halla explícitamente afirmado en 12 (67) y sobreentendido en casi todos los demás textos.

120. Esta primera línea de pensamiento la encontramos en los textos $n .^{\circ} \mathbf{2 , 4 , 5 , 6 , 7}$, $9,10,11,13,14$ y 16

121. Aunque hable siempre de testamento paterno o de nuestro padre. El por qué lo hemos expuesto en nota 98 .

122. El título de heredero, en el derecho romano, podía recaer sobre una o varias personas. Pero en el caso de que existan coherederos, tienen «el carácter de sucesores universales, es decir, la hereditas pasa a ellos en bloque, constituyéndose una comunidad en la que cada heredero tendrá partes ideales y responsabilidad solidaria. Claro que tal comunidad podrá hacerse cesar, pero en la vocación a la herencia ésta es siempre concebida como universalidad que engloba derechos y obligaciones formando unidad» (J. ARIAs Ramos, Derecho, 814-815).

En cuanto a la herencia indivisible en Agustín, cf. 8 (47), 11 (56a), 12 (67).

123. Cf. 8 (47), 11 (56a) y 12 (67). Aunque el haeres o heredero era único, aun pudiendo ser varias las personas que en modo unitario poseían la herencia, ésta de hecho se dividia según lo ordenado por el testador o, en el caso de que faltase prescripción al respecto, según lo establecía la legislación. Cf. J. ARIas Ramos, Derecho, 815.

124. Puede verse en los textos n. ${ }^{\circ} 3$ y 10. En este último asociada a la anterior.

125. Aparece en el texto $n .^{\circ} 17$. 
textos y contextos de las diversas obras y, además, del método de Agustín, quien comienza aplicando ideas a los textos y por respeto al texto acaba modificando las ideas para que cuadren con el texto. Por otra parte, si se mira con un poco de profundidad, se puede advertir que no es tanta la diversidad. Sea un texio u otro, siempre se trata de la Escritura; sea que el testador es el Padre, sea que es el Hijo o Cristo, siempre es Dios; sea que hable de todos los pueblos y de todas las tierras, sea que hable de la paz, sea que hable de Cristo, siempre está hablando de la unidad; por último, sea que mencione a Cristo, sea que mencione a la Iglesia, está hablando de la misma cosa en cuanto que ésta es el Cuerpo de él.

\section{2) La interpretación del testamento}

Tal es, esquemáticamente, el desarrollo que Agustín hace de los textos bíblicos que él considera como testamento divino, o como una claúsula del mismo. Pero en las páginas del santo se perciben otros problemas que podemos definir genéricamente como de interpretación del testamento. Le vemos de vez en cuando precisar bien los personajes. Por ejemplo: ¿Quién es el que dice esto? ¿Es el Padre, o es Cristo? ${ }^{126}$. A veces se requiere la interpretación en sentido propio: $i$ Quién es la semilla a la que se promete en herencia todos los pueblos? Se recurre a un intérprete veraz y capaz, san Pablo. Él dice que es Cristo ${ }^{127}$. Hay que precisar la amplitud de los términos: Cuando se habla de Cristo, se entiende no sólo la Cabeza, sino también todos los miembros; no sólo Jesús, sino los cristianos, miembros de su cuerpo ${ }^{128}$. No basta con leer una parte del testamento solamente; ha de leerse en su totalidad para que no haya escapatoria posible. ¿Cuántas veces lo que parecía favorecer al contrario queda aclarado por las palabras que siguen? ${ }^{129}$. Todo lo dicho posiblemente refleje las discusiones que debian ser frecuentes en la lectura del testamento ${ }^{130}$. A éstas hace referencia con toda probabilidad Agustín cuando afirma que todo está tan claro y manifiesto que no necesita expositor ${ }^{131}, 0$ cuando confiesa que no queda duda sobre la voluntad del testador, perfectamente reflejada en sus palabras ${ }^{132}$. En ningún modo puede decirse que esté oculto lo que Dios quiere ${ }^{133}$.

126. Cf. $9(51)$.

127. Cf. $4(41), 6(45)$; también $13(68), 14(69)$ y $16(71)$.

128. Cf. $12(67)$.

129. Cf. 9 (52).

130. Aunque quizá haya que ver en todo ello reminiscencias retóricas, en concreto, el modo de tratar los Status generis legalis, en especial el que versaba sobre Scriptum et voluntas. Sobre todo ello, cf. H. LAUSBERG, Manual de retórica literaria, Madrid 1966, 184ss.

131. Cf. 7 (46).

132. Cf. $11(64)$.

133. Cf. 8 (47). 


\section{3) A los donatistas, en plan de paz}

La cuestión se ha aclarado. Se ha leído el testamento. Queda claro cuál es la herencia, todos los pueblos, y cuál el heredero, Cristo y los cristianoscatólicos porque sólo éstos poseen aquélla. Ser heredero significa formar parte del Cuerpo de Cristo, porque él es el único heredero. Ser heredero de hecho, significa estar en la auténtica Iglesia, en la verdadera Iglesia, la única que es Cuerpo de Cristo. Queda claro que los donatistas están fuera de la Iglesia porque se hallan fuera del Cuerpo de Cristo; pues si se hallaran en el Cuerpo de Cristo serían coherederos de hecho. La herencia es evidentemente plenitud, totalidad. No pueden estar en posesión de ella los donatistas que sólo hablan de parte de África ${ }^{134}$.

Por otra parte, no se duda de que también ellos quieren ser herederos ${ }^{135}$. ¿Qué han de hacer? Dejar la parte y poseer la totalidad. Salir del territorio extraño a la herencia y ocupar el que ella ocupa. Tal herencia o se la posee to$\mathrm{da}$, o no se la posee en modo alguno. Por otra parte, no les es difícil entrar a poseerla.

- De un lado, la herencia es indivisible: todos los pueblos, la paz. En esto se diferencia de las herencias humanas ${ }^{136}$. Es una herencia para ser poseída en concordia por todos los potenciales coherederos, no para ser dividida mediante disputas ${ }^{137}$. Por muchos que sean los posesores, ella no mengua para cada uno ${ }^{138}$.

- De otro, los coherederos son también distintos. Mientras en el mundo humano éstos tratan de dividir y llevarse cada uno la mejor parte, en relación al testamento divino acontece lo contrario: se desea poseer la herencia juntos. Nadie quiere excluir a los otros, sino tenerlos como coposesores ${ }^{139}$.

Como conclusión de todo, a Agustín no le queda más que la invitación a que entren en la Católica, es decir, en la herencia que está prometida en el testamento del Padre ${ }^{140}$. «Tendrás en herencia los confines de la tierra; ven aquí, poséela en su totalidad juntamente conmigo" ${ }^{141}$.

134. Cf. $7(44), 9(51)$ y $12(67), 13(68)$ y $16(71)$. Textos que cronológicamente se colocan todos en fecha posterior a la legislación antitestamentaria.

135. Cf. 9 (51).

136. Cf. notas 122 y 123 .

137. Cf. 11 (56a).

138. Cf. 8 (47).

139. Cf. 8 (47), $9(51), 11(56 \mathrm{a} .64)$ y 12 (67). Todos estos textos son posteriores a la ley sobre los testamentos y corresponden por tanto al momento en que es mayor la presión para que abracen la unidad que les será impuesta en el 411.

140. Agustín parte de que la Católica es al mismo tiempo la herencia y la heredera. De aquí que invite a los donatistas a formar parte de la herencia y a ser coherederos.

141. Cf. 9 (51). 
El santo quiere además abrirles los ojos, pues ellos no se dan cuenta de que se están haciendo daño a sí mismos. Su conducta es un enconamiento contra ellos mismos ${ }^{142}$. Pudiendo poseer dentro de la concordia la totalidad, quieren conformarse con una parte y litigando ${ }^{143}$. Se les invita a poseer todo lo que se halla en el testamento escrito ${ }^{144}$.

La contienda ha terminado. El juicio ficticio ha concluido. Se ha averiguado cuál es la herencia y, en consecuencia, dónde está. Está en la totalidad católica, no en la parte donatista. El discípulo de Donato ha sido vencido, pero para su bien lo ha sido, porque ha visto que puede recibir más de lo que estaba defendiendo ${ }^{145}$.

Esta es la línea pacificadora que recorre todas las páginas agustinianas y que alcanza su punto más elevado en el período que va del 405 al 411 y en especial en Sermo 358.

\section{4) Contra los donatistas, en polémica}

Pero junto a esa línea pacifista existe, contemporáneamente con ella, otra línea polémica, a veces entremezclada con la anterior, que toma dos direcciones, una de autojustificación y otra de ataque.

De la primera encontramos un ejemplo evidente en la Epístola 93. Agustín se sirve de esta serie de ideas para justificar ante sus opositores la aprobación por parte de él y de las leyes coercitivas imperiales. Entonces, les dirá, se trataba de mantener en vigor el testamento divino, para lo cual parecía oportuno actuar contra los testamentos humanos de los donatistas. Como es admitido por todos, antes es Dios que los hombres. Antes los derechos divinos que los humanos. Agustín no tenía, por esto mismo, otra cosa que hacer ${ }^{146}$.

La segunda tiene varios aspectos.

Un testamento puede ser falsificado. En concreto, los donatistas acusaban a los católicos de falsificadores basándose en una comparación, es decir: quien entregase a las llamas el testamento de un hombre muerto sería castigado como falsificador. Ahora bien, esto mismo es lo que han hecho los católicos quienes han enviado al fuego a la Escritura, testamento de Dios ${ }^{147}$. Tal es su forma de razonar. Si han quemado el testamento, en ningún modo pueden

142. Cf. 7 (46).

143. $I b$.

144. 12 (67): «Ecce totum tene quod in tabulis».

145. 9 (51): «Quare litigando vocas ad partem? Huc veni, bono tuo vinceris, totum habebis»".

146. Cf. $10(56)$.

147. Cf. $5(42)$. 
poseer la herencia que en él se contenía. Puede decirse que han renunciado a ella ${ }^{148}$.

En su respuesta, Agustín cambia los términos y al mismo tiempo los planos de la discusión. Petiliano le arguía desde el testamento sobre la herencia. Agustín sigue el' proceso inverso: de la herencia al testamento. Del hecho de que poseen aquélla los católicos, concluye que no han destruido éste. ¿Cómo se puede explicar que los católicos hayan prendido fuego al testamento y se hallen en posesión de la herencia allí escrita? Por otra parte, ¿no es extraño que los donatistas hayan conservado el testamento, según dicen, y hayan perdido la herencia, herencia que por otra parte está clara? ${ }^{149}$. Por tanto, ¿quién puede gloriarse de haber conservado el testamento? Para los donatistas la respuesta es clara: sólo ellos porque eran los herederos o sucesores de quienes no habían entregado a las llamas tales libros sagrados. Agustín les replicará: en ningún modo puede gloriarse de méritos en este aspecto, porque ellos mismos han destruido el testamento o al menos son los herederos de los traditores de otros tiempos ${ }^{150}$. La argumentación es la siguiente: entregó el testamento a las llamas quien no está de acuerdo con lo que en él se halla establecido ${ }^{151}$, quien no lo sigue ${ }^{152}$ o no cumple lo que ordena ${ }^{153}$.

Pero existe también otra línea de razonamiento. Ha conservado el testamento, es decir, no es traditor del mismo quien conserva la herencia en él prometida ${ }^{154}$. Conservar la herencia es prueba evidente de haber conservado el testamento. El razonamiento puede ser el siguiente: manteniendo legítimamente la herencia legada se está cumpliendo el testamento, se le mantiene en vigor y no puede hablarse, por tanto, de haberlo destruido o mandado a las llamas.

Aquí conviene recordar algo a que ya hicimos alusión en más de una ocasión al hacer el análisis de los textos. Está claro que Agustín de una forma consciente se coloca en un plano distinto al de los donatistas. Éstos acusaban a los católicos de haber destruido el testamento de Dios enviándolo al fuego.

148. Sobre la aceptación de la herencia por parte del instituido heredero, cf. J. ARIAS RAmos, Derecho, 873ss.

149. Cf. 5 (42). Podría parecer que en la argumentación de Agustín existe un sofisma. En efecto, ¿cómo es posible conocer la herencia dejada por el testador si el testamento ha sido dadoa las llamas o, mejor, falsificado, según las palabras de Petiliano cont. Litt. Pet. Il, 8,20) por quienes ahora arguyen desde él? Pero no existe tal sofisma porque Agustín no tiene reparos en tomar el testamento venga de donde venga, aun de manos donatistas que afirman ser ellos quienes lo han conservado. De este mismo hecho sacará toda la fuerza de su argumentación. Cf. 15 (70). Por eso Agustín podrá decir: «Obiece mihi de testamento quod voles» (Contra Lit. Pet. II, 8,20), o sea, no me importa que me acuses de haber quemado el testamento, siempre queda, conservado por otros, los donatistas incluidos, para argumentar contra ellos.

150. Cf. 4 (41).

151. Cf. $4(41)$

152. Cf. $9(51)$.

153. Cf. 11 (65).

154. Cf. 5 (42). 
Agustín les responde que no pueden presumir de haberlo conservado, puesto que no cumplen lo establecido en el mismo. Los donatistas quieren discutir un problema histórico; Agustín se pasa al campo de las ideas: Se trata, por tanto, de una salida por la tangente, aunque muy consciente.

La acusación contra el donatismo se alarga más todavía. No solamente no siguen lo preceptuado en el testamento; no sólo se oponen a las palabras y a la voluntad del testador, sino que hasta intentan hacer irritum, inválido ${ }^{155}$, ese testamento y se atreven a hacer adiciones al mismo, algo que no ocurre ni con el testamento humano según el testimonio de san Pablo en su carta a los Gálatas ${ }^{156}$.

La polémica antidonatista presenta todavía algunos aspectos que merecen ser reseñados.

Los seguidores de Donato no tienen por qué quejarse de lo que les ha sobrevenido. Es la justa pena a su modo de proceder. Se ha hecho con ellos lo mismo que ellos han hecho con Dios ${ }^{157}$. Lo que ellos han hecho con el testamento de Dios, Dios lo ha hecho con el de ellos a través de los emperadores. Pero no han de olvidar que esta acción de Dios no es castigo, sino corrección. Es una pena medicinal ${ }^{158}$. Así brilla la compasión de Dios frente a los donatistas quienes en su conducta tienen un agravante. Su ofensa no la hacen a un testador ya muerto, sino a uno que vive y en el cielo ${ }^{159}$. Es ésta una diferencia que Agustín recalca con frecuencia, entre el testamento humano y el divino. Él primero tiene valor en tanto en cuanto el testador ha muerto ${ }^{160}$. En el segundo, las cosas están de otro modo: el testador vive. Vive Dios Padre; el mismo Cristo, aunque murió, resucitó y sigue viviendo en el cielo y velando por su testamento ${ }^{161}$.

De todo lo dicho anteriormente se sigue que los donatistas son peores no

155. Testamentum irritum era aquel que se había hecho inválido por capitis deminutio del testador (cf. J. Arias Ramos, Derecho, 821). Agustín utiliza este término porque lo encuentra en la traducción latina de la Biblia de que se sirve, pero probablemente sin darle valor técnico. Simplemente quiere decir que el testamento es nulo.

156. Cf. 6 (45) y 14 (69). Lo hacen irritum al afirmar que no se ha cumplido. Es decir, se trata de una invalidez de hecho, no de derecho. Añaden algo al afirmar que la herencia de Cristo es solamente África o el partido de Donato, cosa que no se encuentra escrita en ninguna claúsula del testamento.

157. Cf. 11 (58): «Videte quam digna sit poena». Cf. también 11 (60).

158. Sermo 47, 22; CC 41,596: «Evigila ex dolore tuo, corrige ex cruciatu tuo. Ligno male curvo nosti calorem solere adhiberi; corrigat te dolor iste. Nondum est flamma ignis aeterni. Tamquam calor foci est admotus curvo cordi tuo, ut hinc admoneatur et corrigatur».

169. Cf. 3 (36), 4 (43), 9 (51) y 11 (59).

160. En. in Ps. 82,6, CC 39,1142: "Testamentum dicitur quod non valet nisi testatoribus mortuis». La muerte del testador es un elemento esencial para que el testamento tenga valor, pues, como señalamos en la definición es un acto revocable. Solamente cuando haya muerto el testador no podrá ser revocado.

161. A los textos agustinianos citados en n. 159 hay que añadir el de Optato: 1 (31). 
sólo que Abrahán, lo cual es evidente, sino hasta peores que los mismos judíos ${ }^{162}$.

Es inútil, pues, que discutan con Agustín. El santo no hace otra cosa que repetir lo que dicen las Escrituras, el testamento. Que discutan, si aśí lo desean, con ellas. Es el consejo del obispo ${ }^{163}$.

A veces Agustín se sirve también del sarcasmo como medio de ataque a los donatistas. A ello servía perfectamente su óptima preparación retórica y la facilidad, de ella derivada, para jugar con las palabras y con los conceptos ${ }^{164}$.

\section{5) A los católicos, confianza}

A partir de estas ideas sobre la Escritura como testamento de Dios y lo que ello encierra, también Agustín tiene palabras que dirigir a los católicos. Son ante todo palabras de ánimo, de invitación a guardar la herencia, a mantenerse en la totalidad, porque ello es prueba evidente de hallarse en el testamento del padre y no existe posibilidad de que se nos quite, porque él mismo, a diferencia de lo que suele suceder en lo humano, será quien juzgue en base a él, y obviamente dictará sentencia en favor del que él ha constituido como heredero ${ }^{165}$.

\section{6) Resumen}

Vamos a intentar a continuación exponer lo más esquemáticamente posible cuanto hemos escrito en este tercer apartado del presente artículo.

La experiencia que tuvo de juez aportó a Agustín el molde para dar forma a la discusión entre católicos y donatistas.

Ambos grupos cristianos pretendían estar en posesión de hecho de la herencia legada por Dios. Como se trataba de dos posturas contrarias, en ambas partes no podía estar la verdad. Se idea un recurso ficticio a un juez. A él se va con el testamento en mano. Este testamento, y en esto coinciden las dos partes, es la Escritura. Agustín trata, pues, la Escritura como un testamento, procurando, eso sí, anotar las diferencias inevitables respecto a cualquier testa-mento humano, porque ellas le servirán para su causa. Son las siguientes:

a) En el testamento divino se da el caso de que el testador aún sigue viviendo, tras haberse abierto el testamento.

162. Cf. 11 (63) y $5(43)$ : «Itane vero parceret Christo in terra ambulanti, qui contradicit in coelo sedentin?

163. Cf. 5 (43) y 9 (51).

164. Cf. 9 (51): «Nos servavimus Scripturas ne arderent? Servatae sunt unde tu ardeas». También 11 (65).

165. Cf. 3 (36). 
b) La herencia legada es algo infinitamente superior a lo que puede dejar cualquier hombre.

c) Contrariamente a la herencia humana, la herencia divina es indivisible. O se la posee toda, o no se la posee. Tampoco mengua la parte de cada uno por el hecho de que aumenten los cohereteros.

d) También es distinto el coinportamiento de los herederos: no buscan la división, sino la posesión en común.

e) El testamento divino se cumple siempre.

f) El juez que interpreta el testamento divino es el mismo testador.

Entrando ya en el testamento en sí, después de haber sido leído e interpretado, resulta claro que:

a) El testador es Dios (el Padre o Cristo).

b) La herencia es la totalidad de la tierra y la paz que se identifica con aquella porque existe alli donde no hay partes.

c) El heredero es Cristo.

d) Los coherederos son los cristianos, la Iglesia.

Por tanto, los donatistas han de reconocer que son los catolicos quienes de hecho poseen la herencia, quienes han mantenido el testamento, porque poseen la totalidad y la paz (en cuanto que buscan la concordia y no el litigar). Han sido vencidos los donatistas por la lectura del testamento, pero esto ni les humilla ni les quita nada, sino que les favorece en cuanto que el testamento les otorga más de aquello por lo que ellos luchaban: luchaban por la parte y se les ofrece la totalidad. De aquí la invitación constante a tomar posesión de la auténtica hérencia. Nada se lo impide: ni la cualidad de la herencia, ni los restantes coherederos.

Es evidente que esta línea pacifista corre por las páginas agustinianas. Pero no lo es menos que junto a ella, mezclada en los mismos textos se encuentra otra más polémica que sintetizamos en los siguientes puntos:

a) Agustín se autodefiende.

b) Ataca a los donatistas:

- No tienen derecho a quejarse. Se ha hecho con ellos lo que ellos hicieron con Dios.

- Aunque no se cansen de acusar a los católicos, son ellos quienes efectivamente no han conservado el testamento, porque no mantienen lo establecido en él.

- Ellos son, por tanto, los continuadores o herederos de los traditores del tiempo de las persecuciones.

- No conformes con ello, pretenden que haya sido inefectivo el testamento de Dios y osan añadirle algo.

Desde todos estos puntos de vista, pues, el juez no puede dictar sentencia 
sino a favor de los católicos. Se acabó la contienda o debería acabarse, al menos en teoría.

\section{7) Repercusiones de la ley del año 405}

Comenzamos este trabajo haciendo referencia a un hecho histórico concreto: la legislación del emperador Honorio que privaba a los donatistas de la capacidad tanto de testar como de recibir en testamento, a no ser que se pasasen a la fe católica; hecho del que apenas hemos hecho mención a lo largo de estas páginas. Surge, por tanto, una pregunta: ¿Se ha dejado sentir en la predicación agustiniana $o$, más en general, en la obra del santo? ¿Hasta qué punto ha modificado, si es que lo ha modificado, los pensamientos del obispo? Nuestra respuesta va a ser breve y esquemática.

En pocas palabras, puede afirmarse que existen varios puntos que se mantienen constantes en toda su obra sin que haya diferencia entre el antes y después de la ley, al mismo tiempo que existen otros que hacen su aparición solamente tras la promulgación de la misma.

Se mantienen constantes los siguientes puntos:

a) La concepción de la Escritura como testamento de Dios en el significado propuesto en el comienzo de este trabajo.

b) El servirse de Gen 22,18, Sal 2,8 y Gal 3,15-16 como claúsulas en que queda especificado quién es el heredero (Cristo y los cristianos, sus miembros) y en qué consiste la herencia (todos los pueblos) ${ }^{166}$.

c) La constatación e insistencia en el hecho de que en este caso el testador está vivo. tes.

d) La invitación a comulgar con la herencia, es decir, con todas las gen-

e) La polemica sobre quién ha conservado el testamento y quién ha sido el traditor ${ }^{167}$.

f) La acusación a los donatistas de haber pretendido hacer inválido el testamento de Dios ${ }^{168}$.

Tras la promulgación de la ley, se constatan los siguientes aspectos nuevos:

a) Consideraciones sobre el estado de ánimo de los donatistas; el sentimiento de ira e indignación por la ley.

166. Otros textos bíblicos al ser esporádicos no pueden mencionarse. Ya los recordamos con anterioridad. Conviene anotar también que Gal 3,15-16 solamente aparece en textos escritos, nunca en textos de predicación.

167. Existe también una forma un poco diversa de plantear la misma cuestión: ¿quiénes son los herederos de los traditores del pasado? Sólo aparece en la primera época anterior a la promulgación de la ley.

168. Sólo en textos originariamente escritos. 
b) Los esfuerzos que hacían para librarse de la ley en la práctica.

c) Los textos y comentarios agustinianos son más amplios ${ }^{169}$.

d) Se recurre a la Biblia en su cualidad de testamento. No solamente se la concibe y se discute sobre la Escritura como testamento, sino que se da el recurso a él para hallar solución al litigio entre dos hermanos por una posesión ${ }^{170}$.

e) Aparece el texto de Jn 14,27 como expresión del testamento de Cristo.

f) La paz como herencia que no puede dividirse.

g) Aparece el lenguaje de litis-concordia y pars-totum.

h) Se hace más apremiante la invitación a la unidad que se concibe como participación en común de la única herencia de Cristo.

\section{CONCLUSIÓN}

Si algo caracteriza al donatismo es su capacidad de haber planteado un problema de amplios horizontes a partir de un hecho concreto, que se había repetido es más de una ocasión ${ }^{171}$. Lo que podía haber pasado a la historia como la simple demostración, una más, de la verdad de las palabras del Señor de que aunque el espíritu sea fuerte la carne es flaca (Mt 26,41) se convirtió en un problema de dimensiones insospechadas en un primer momento. Un hecho histórico se convierte o da paso a un problema teológico. Una situación de hecho plantea un problema de derecho: ¿Cómo ha de ser la auténtica Iglesia de Cristo? Y, yendo más adelante, ¿dónde está esa Iglesia?

Se trata, sin duda, de un problema interno del cristianismo. Como ya decía san Optato, aunque a propósito del bautismo, pero siempre dentro de la controversia antidonatista, los árbitros externos no sirven, sean paganos o judíos ${ }^{172}$. ¿Dónde hallar, pues, un juez neutral, que no sea ni de una parte ni de otra y al mismo tiempo acaten ambas su autoridad? El único posible es la Biblia, aceptada por ambos bandos contendientes. El debate es en realidad un proceso, un juicio con todo el aparato forense. Concretizando más, el proceso es entre hermanos que disputan por una posesión. La Biblia es en este caso el código conforme al cual se juzgará. Limitándonos al aspecto que hemos estu-

169. En ellos Agustín se detiene a hablar expresamente sobre el testamento como recurso para resolver el conflicto, no lo hace sólo de pasada.

170. Es en esta época en la que aparece más evidente el carácter forense de los textos agustinianos.

171. El problema de los lapsi era corolario casi obligatorio de toda persecucion. Ya en Africa se habían sentido turbados por estos problemas. Baste leer las obras de san Cipriano.

172. Cf. 1 (31). 
diado, podremos decir que la Biblia en sí no es un código legal, pero que puede hacer de criterio de discernimiento en cuanto testamento legalizado y por tanto amparado por la ley.

En última instancia, lo que está en discusión es lo siguiente: ¿cuál es la auténtica Iglesia de Cristo: la Católica o la Donatista? Para poder llegar a una solución positiva se impone dar un paso más y conocer cómo debe ser la Iglesia. Unos y otros están de acuerdo en que ella es la realización de la promesa de Dios, en que es la herencia que el padre dejo a Cristo. ¿Cómo es entonces esa herencia? La respuesta se hará sencilla recurriendo al testamento. Es en este momento de la controversia en el que se coloca todo lo que hemos tratado. Leídos los pasajes de la Escritura que por distintos motivos pueden ser considerados como claúsulas que describen esa herencia, se descubre como nota característica la universalidad, la catolicidad. A partir de aquí será fácil sacar conclusiones. Si la herencia de Dios (Iglesia, por concesión unánime) tiene por nota característica la universalidad o catolicidad, donde exista ésta, existirá aquélla. En cierto modo, el problema se resuelve con el simple recurrir a la geografía. Y no porque la geografía de por sí sea criterio teológico, sino porque la promesa de Dios nadie puede anularla. La fidelidad de Dios está por encima de la debilidad humana. El renunciar a esta catolicidad de hecho y de extensión, sería pretender que la promesa de Dios, que su testamento ha quedado sin cumplimiento. En definitiva, la Iglesia católica en cuanto la única y verdaderamente universal, con universalidad de hecho, no sólo de derecho ${ }^{173}$, es la auténtica Iglesia de Cristo. Así hemos llegado al centro de la discusión, que se ha resuelto en favor de la tesis de Agustín. El de facto, va de acuerdo con el de iure. La Iglesia católica es la auténtica Iglesia de Cristo.

Pío de Luis Vizcafno

173. Más que de catolicidad de derecho habría que hablar de catolicidad de tendencia, la admitida por los donatistas para su Iglesia. Cf. sobre todo esto último, J. RATZINGER, Volk und Haus Gottes in Augustins Lehre von der Kirche, München 1954, 127-135. 